\title{
Geossistemas E Geografia No BRASIL
}

\author{
Lucas Costa de Souza Cavalcanti, Antônio Carlos de Barros Corrêa \\ Universidade Federal de Pernambuco
}

\begin{abstract}
Resumo
A geografia brasileira tem dispensado atenção especial à ideia de geossistemas, considerada base teórica e metodológica inspirada em trabalhos de geógrafos estrangeiros, sobretudo franceses e soviéticos. Este trabalho analisa aspectos conceituais e terminológicos da teoria dos geossistemas visando uma melhor compreensão de seu significado e aplicação. Para tanto, diversas interpretações sobre os geossistemas foram avaliadas, tendo por critério a biografia dos autores, as suas referências e ferramentas interpretativas disponíveis, bem como seus pressupostos. O trabalho permite compreender que o horizonte epistemológico alcançado pela teoria dos geossistemas permitiu integrar diferentes perspectivas para o estudo de áreas naturais. Não obstante, a teoria em questão ainda apresenta certa dificuldade de interpretação e aceitação no Brasil por vários motivos.
\end{abstract}

Palavras-chave: geografia física; geossistemas; geografia brasileira.

\begin{abstract}
Brazilian geography has paid special attention to geosystems as a theoretical and methodological base inspired by foreign geographers, moreover French and Soviet former. This paper deals with the question of geosystems use in Brazilian geography evaluating this understanding and application. The results allow us to understand the epistemological horizon reached by the theory of geosystems to integrate different perspectives to the study of natural areas. Notwithstanding, the theory in question still has some difficulty in interpretation and acceptance in Brazil for several reasons.
\end{abstract}

Key words: physical geography; geosystems; Brazilian geography.

A ssim como em outros países, o Brasil também assistiu, e tem assistido, ao desenvolvimento da ideia de áreas naturais como produto das relações entre os componentes da natureza na superfície terrestre. Esta ideia pós-iluminista foi incorporada às agendas das instituições de ensino e pesquisa, assumindo conotações e objetivos distintos e, materializando-se na forma de termos também diferentes como regiões naturais, ecorregiões, unidades geoambientais, geossistemas, entre tantos outros (CAVALCANTI \& CORRÊA, 2014).

Entre os geógrafos brasileiros, o termo geossistema passou a figurar constantemente como aplicação da teoria dos sistemas ao estudo de áreas naturais. Pesquisadores renomados da ciência geográfica de nosso país não se eximiram de tecer suas considerações sobre os geossistemas e/ou a teoria geossistêmica e sua aplicabilidade à compartimentação e estudo da dinâmica e evolução das paisagens do Brasil, destacando-se os nomes de Antonio Christofoletti, Aziz Nacib Ab'Sáber, Carlos Augusto de Figueiredo Monteiro e Helmut Troppmair.

Muitos dos artigos publicados por estes autores encontram na epígrafe 'geossistema', uma 
base teórica e metodológica inspirada em trabalhos de geógrafos estrangeiros, sobretudo franceses e soviéticos. Esta filiação deriva do fato de que o termo geossistema foi introduzido no Brasil a partir do artigo "Paysage et géographie physique globale: esquisse méthodologique" escrito pelo francês Georges Bertrand ${ }^{1}$ em 1968 e publicado no Brasil em 1972, sob tradução de Olga Cruz. Contudo, poucos anos depois, em 1975, por ocasião do $24^{\circ}$ Congresso Geográfico Internacional (realizado pela União Geográfica Internacional, em Moscou), Carlos Augusto de Figueiredo Monteiro teve oportunidade de conhecer as práticas físico-geográficas que se desenvolviam na União das Repúblicas Socialistas Soviéticas (URSS), chegando inclusive a receber livros de presente do letão Adolph A. Krauklis, com quem fez amizade (MONTEIRO, 2009, comunicação pessoal).

Recebendo também uma versão em inglês de um texto preparado pelo geógrafo Viktor B. Sochava ${ }^{2}$, denominado "The Study of Geosystems", Carlos A.F. Monteiro introduziu no nosso país a concepção siberiana da Ciência da Paisagem soviética, que difere grandemente daquela de Georges Bertrand. Contudo, as interpretações posteriores dos geógrafos brasileiros passaram, muitas vezes a tomar a posição de Sochava como sinônima da de Bertrand, além de tecer considerações sobre as dimensões espaciais e temporais dos geossistemas como sendo entidades de grande abrangência areal, que é coerente com a concepção desenvolvida pelo francês, mas não com a do russo.

Considerando tudo isto, o objetivo deste trabalho é esclarecer aspectos conceituais e terminológicos da teoria dos geossistemas, na acepção de Sochava e no contexto da geografia russosoviética, contribuindo assim, para desfazer e evitar confusões de nomenclaturas e metodologia que possam surgir (ou que já surgiram) quando se faz a apreciação do termo geossistema.

\section{Aspectos metodológicos}

A difusão de qualquer conhecimento se depara com os limites dos horizontes cognitivos dos sujeitos e só compreendemos aquilo que nos está disponível para conhecer (HACKING, 2008). Numa apreciação hermenêutica, toda ideia exposta (seja em texto ou outro meio de informação) possui um sentido impresso pelo autor, mas está sujeita a uma variação de significados em função dos métodos de interpretação utilizados, tanto quanto das ferramentas e referências disponíveis para sua compreensão (LOPES, 2004).

Buscando o esclarecimento de aspectos fundamentais da teoria dos geossistemas e sua difusão no Brasil, foram analisadas diversas interpretações sobre a concepção de geossistemas em

\footnotetext{
${ }^{1}$ Georges Bertrand (1932-) professor da Universidade de Toulouse - Le Mirail (França). Foi diretor do Centro Interdisciplinar para o Estudo do Ambiente Natural e da Organização Rural (CIMA) do Conselho Nacional de Pesquisa da França (CNRS). Na década de 1970 foi um dos grandes expoentes da renovação da geografia física francesa, juntamente com Jean Tricart (VEYRET \& VIGNEAU, 2002).

${ }^{2}$ Viktor Borisovich Sochava (1905-1978) nasceu em São Petersburgo (Rússia) e foi diretor do Instituto de Geografia da Sibéria e do Extremo Oriente (hoje Instituto Viktor Sochava de Geografia). Formado em ciências agrárias e com doutorado em biologia, foi um dos maiores contribuintes da história da geografia russo-soviética. Propôs a Teoria dos geossistemas como uma renovação e revisão da noção de paisagem como entidade real, integrando e ampliando o espectro epistemológico e metodológico da geografia física.
} 
Bertrand e em Sochava. Neste sentido, diversos textos produzidos no Brasil sobre a referida epígrafe, tiveram suas interpretações avaliadas tendo por critério a biografia dos autores, as suas referências e ferramentas interpretativas disponíveis, bem como seus pressupostos.

De forma a esclarecer e justificar nossa empresa, na medida em que fomos avaliando os textos, foi realizada uma análise comparativa mais ampla destes em relação às propostas de Bertrand e Sochava. Deste modo, contribuímos para dirimir a criação de significados que se afastem do sentido proposto originalmente pelos autores.

Assim, nossos resultados se iniciam com uma exposição simples sobre as relações entre as propostas de Bertrand e Sochava e desenvolve-se tratando das dimensões espaciais e temporais dos geossistemas, destacando divergências na compreensão do sentido original proposto pelo geógrafo francês e pelo russo também. Por fim, apresenta-se uma breve proposição acerca das raízes das divergências enlevadas, expondo, deste modo, limites e perspectivas para o desenvolvimento e difusão da teoria dos geossistemas no Brasil.

\section{Geossistemas em Bertrand e em Sochava}

Existe uma diferença fundamental na concepção de geossistemas entre Bertrand e Sochava, ou seja, mesmo ambos utilizando a mesma epígrafe, apresentam concepções distintas da palavra. Mesma palavra, ideias diferentes.

No artigo de 1968, Bertrand utiliza a palavra geossistema para se referir a uma das escalas espaço-temporais da paisagem, abrangendo a $4^{\mathrm{a}}$ e $5^{\mathrm{a}}$ ordem de grandeza na classificação de Cailleux e Tricart, abrangendo escalas espaciais da ordem de 10 a $10^{2} \mathrm{~km}^{2}$ e temporais da ordem de $10^{6}$ a $10^{7}$ anos. Neste momento, a concepção de geossistema em Bertrand tem dimensões espaciais e temporais bem definidas.

Isto seria modificado posteriormente, quando Bertrand passa a escrever artigos com o georgiano Nikolai L. Beruchashvili e assume que seu conceito de geossistema como uma dimensão de ordem de grandeza definida é menos coerente que aquela da proposta de Sochava, afirmando que:

Em 1964-1965, nós havíamos definido o geossistema como uma unidade taxocorológica entre outras (geótopo - geofácies - geossistema - região natural - domínio geográfico zona). O geossistema representava um espaço natural homogêneo dividido em geofácies. [...] Num esforço de uniformização conceitual e de simplificação da linguagem, nós, entretanto, estamos de acordo, com a definição mais lógica de V.B. Sochava, que faz do geossistema, como do ecossistema, uma abstração e um conceito (BEROUTCHACHVILI \& BERTRAND, 1978, p. 168, tradução nossa). ${ }^{3}$

\footnotetext{
3 “En 1964-1965, nous avions defini Le géosystème comme une unité taxochorologique parmi d'autres (géotope géofaciès - géosystème - région naturelle - domaine géographique - zone). Le géosystème représentait um espace naturel homogéne divisé en géofaciès. Cette définition taxonomique a été utilsée par d'autres auteurs aussi bien dans la recherche fondamentale que dans dês travaux d'application. Les études que sont contenues dans ce numéro de la Revue Géographique des Pyrénées et du Sud-Ouest et lês légends des cartes se conforment à CET usage.Dans un souci d'uniformisation conceptuelle et de simplification du language, nous nous rallions cependant, avec le CIMA, à la définition plus lógique de V.B. Sochava, qui fait Du géosystème, comme de l'écosystème, une abstraction et un concept."
} 
Refletindo sobre isso, Georges Bertrand muda sua concepção do termo geossistema, passando a compreendê-lo como uma entidade natural formada pelas relações entre os componentes da natureza e impactada pela ação da sociedade. Esta nova concepção, inclusive é utilizada para formular seu modelo Geossistema-Território-Paisagem (GTP), respectivamente associados às noções de source, resource e resourcement (BERTRAND \& BERTRAND, 2002).

Contudo, a origem do conceito de geossistema está associada à decisão da Sociedade Russa de Geografia em propor a unificação terminológica de conceitos e termos em geografia física. A partir deste desafio inicial, Viktor Borisovich Sochava (1905-1978), propôs em 1963, que o termo geossistema fosse utilizado para substituir o termo paisagem, que era comumente utilizado na então geografia soviética (SEMENOV \& SNYTKO, 2015).

Para Sochava, o termo paisagem deveria ser substituído, sobretudo em função de sua polissemia e seu uso em diversas disciplinas. Neste sentido, o termo geossistema seria mais adequado ao referir especificamente às formações naturais que se manifestam na superfície terrestre (SEMENOV \& SNYTKO, 2015).

Assim, Viktor B. Sochava formula o termo geossistema em 1963, no artigo intitulado "Definição de alguns conceitos e termos da geografia física", definindo-o como: "unidade natural de todas as categorias possíveis, do geossistema planetário (envelope geográfico ou ambiente geográfico em geral) ao geossistema elementar (fácies físico-geográfica)" (SOCHAVA, 1963, p. 53). Assim, diferentemente de uma escala espacial bem definida, como é o caso da proposta de Bertrand, a conceituação de Sochava é genérica, na qual o geossistema pode possuir uma ampla gama de dimensões espaciais na superfície terrestre, indo desde a fácies físico-geográfica até o envelope geográfico (toda a superfície planetária).

Em sua definição, o geógrafo russo faz referência a estes dois conceitos (envelope geográfico e fácies físico-geográfica), que vamos apresentar em detalhes a seguir. Ambos os termos já estavam plenamente desenvolvidos na geografia soviética pelo menos desde a década de 1940, sobretudo com a publicação dos trabalhos de Nicolai A. Solntcev (KALESNIK, 1964; ISACHENKO, 1973).

\section{Unidades físico-geográficas}

Uma definição detalhada de envelope geográfico é apresentada por Isachenko (1973) e corresponde à parte externa da crosta terrestre que inclui a litosfera (com 4 a $5 \mathrm{~km}$ de espessura), a hidrosfera, a troposfera (altitude entre 8 e $16 \mathrm{~km}$ ) e a biosfera. Esta região do planeta funciona como um sistema complexo em que elementos bióticos, abióticos e humanos interagem, produzindo como estrutura emergente as paisagens (RODRIGUEZ et al., 2004).

No outro extremo, a fácies físico-geográfica ou simplesmente fácies - фрация (Fig. 1) constitui a menor unidade numa divisão natural do terreno. Ela já aparecia em trabalhos do final do século 19 e início do século 20, como a noção de epimorfo, em Abolin (1904), definida como uma unidade de relevo (ex.: o topo do morro, ou sopé da encosta, etc.), sendo caracterizada pela uni- 
formidade da rocha-mãe, microclima, regime de drenagem e umedecimento do solo, migração geoquímica, pédon e localização dentro de uma comunidade ecológica (ISACHENKO, 1973; 1991).

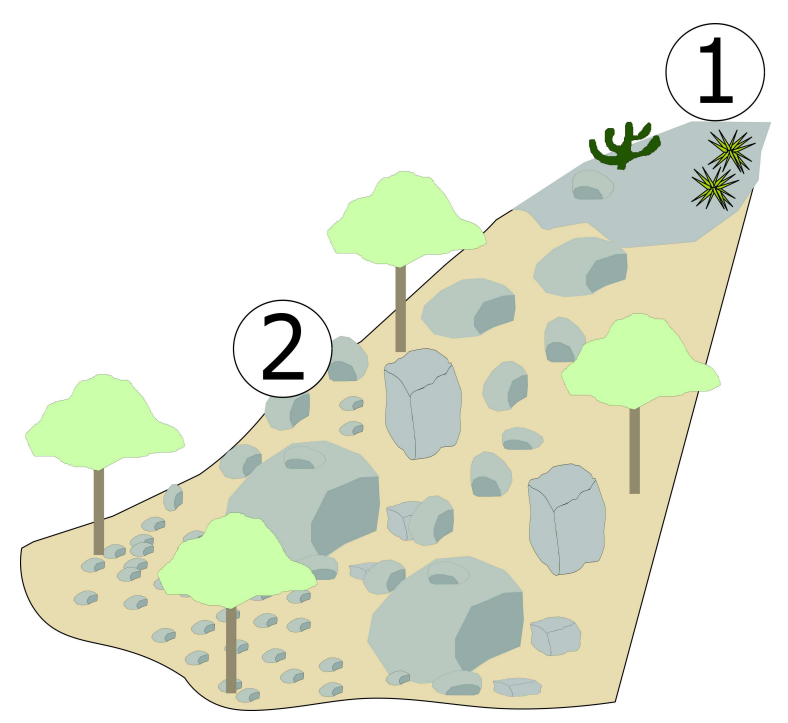

Figura 1. Fácies ao longo de uma encosta no semiárido brasileiro. 1- Segmento de encosta rochosa com bromélias e cactos; 2 - Tálus com Anadenanthera colubrina. Fonte: os autores.

Sochava (1978) denominou a fácies de geômero elementar. Contudo, o mesmo fez a ressalva de que em área afetadas pelo uso da terra, seria possível encontrar, num mesmo segmento de encosta com único litotipo e condições de drenagem, diferentes comunidades vegetais. Neste caso, pode-se subdividir a fácies em unidades intermediárias denominadas biogeocenoses, espécie de fácies ou ainda fácies elementar.

Entre as fácies e o envelope geográfico é descrita uma série de unidades naturais que, em sínteses naturalistas recebem nomes diversos, como já foi visto. Exemplos correspondentes são os complexos biogeocenóticos de Walter (1986) ou as famílias de ecossistemas de Ab'Sáber (2003).

$\mathrm{Na}$ Geografia russo-soviética, um modelo destas subunidades físico-naturais intermediárias se tornou consagrado, sendo inclusive incorporado na proposta de Sochava. Este modelo inclui agrupamentos hierárquicos de fácies para distinção do ambiente geográfico de dimensões locais a mesorregionais, sobretudo a partir de N. A. Solntcev.

No referido modelo, uma associação funcional de fácies (chamada por Sochava de geócoro elementar) é definida em função da hidrodinâmica da encosta ou do ambiente fluvial. Esta unidade foi anteriormente chamada por Solntcev de subtrato (Podurochische - подурочище, em russo). A associação funcional de geócoros elementares constitui um microgeócoro ou trato (Urochische урочище, em russo) (Fig. 2). 


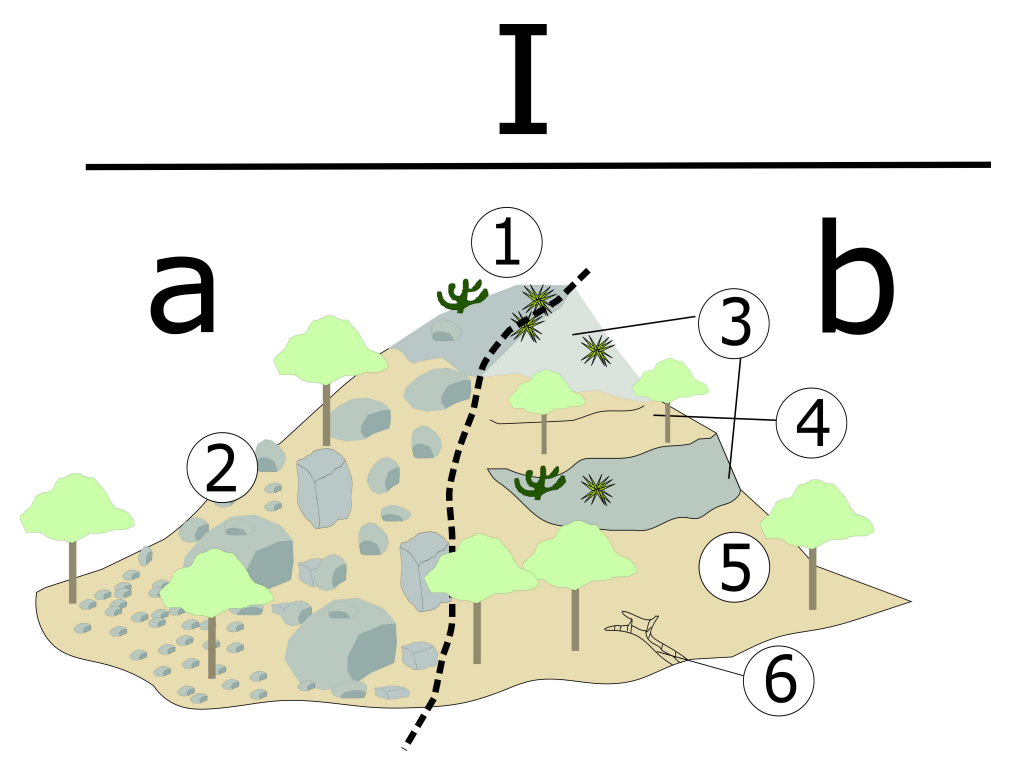

Figura 2. Associação funcional de fácies (geócoros). I - Trato (microgeócoro) de inselberg com caatinga de Anadenanthera colubrina com cactos e bromélias em lajedos; la - Subtrato (geócoro elementar) com associação lajedotálus; lb - Subtrato (geócoro elementar) com associação lajedo-patamar estrutural-lajedosopé coluvial. 1 a 6 - Fácies. Fonte: os autores.

Neste contexto, o conceito de Estilos Fluviais (River Styles $®$ ) em Brierley e Fryirs (2000) pode ser encarado como um subtrato, em que cada geomorphic unit corresponderia a uma fácies distinta. Para os referidos autores, um estilo fluvial abrange uma seção do ambiente fluvial com mesmo tipo de confinamento das margens e que apresenta mesmo conjunto de unidades geomórficas com gênese comum. Esta noção é análoga à de geócoro elementar.

Percebe-se que mesmo se tratando de uma abordagem holística, a morfodinâmica condiciona a definição das unidades. É um princípio que pode ser melhor compreendido pela afirmação de Tricart (1977, p.29): "do ponto de vista ecológico, a morfodinâmica é uma limitação". Assim, entende-se que tanto a pedogênese quanto a sucessão ecológica podem-se dar apenas num contexto de menor instabilidade morfodinâmica.

Seguindo a mesma lógica, Solntcev destaca as áreas naturais formadas pela interação funcional de tratos, que ele denominou de paisagem (landschaft ${ }^{4}$ - ландшарт). As paisagens, geralmente apresentando uma dimensão mesorregional (10 a $10^{2} \mathrm{~km}^{2}$ ), estão mais próximas do conceito de geossistema de Bertrand (1968), sendo denominadas por Sochava de macrogeócoros (ver a seguir).

Uma Paisagem geralmente reflete um mesoclima atuando sobre uma determinada morfoestrutura, ou seja, consiste numa associação entre processos geológico-geomorfológicos e bioclimáticos mesorregionais. Em 1948, Solntcev definiu uma paisagem geográfica como "uma área geneticamente homogênea, com uma repetição regular de combinações inter-relacionadas da estrutura geológica, formas de relevo, águas superficiais e subterrâneas, microclimas, solos, fito e zoocenoses" (SOLNETSEV, 2006, p. 19). ${ }^{5}$

Internamente, a paisagem (macrogeócoro) apresenta um mesmo conjunto funcional de tratos, subtratos e fácies (Fig. 3). Este conjunto é denominado de estrutura morfológica da paisagem

\footnotetext{
${ }^{4}$ A língua russa não possui uma palavra para paisagem, desta forma eles emprestam o termo alemão landschaft.

${ }^{5}$ Aqui fica claro o quanto a concepção de paisagem da geografia russo-soviética destoa de algumas concepções no Brasil (Cf. CAVALCANTI, 2014).
} 
(ISACHENKO, 1991; SOLNETSEV, 2006). Nesta estrutura, algum tipo de trato pode ser mais comum do que outros, sendo chamado de dominante. Outros tipos de tratos podem ainda ser considerados secundários ou ainda, raros, quando ocorrem em menor proporção.

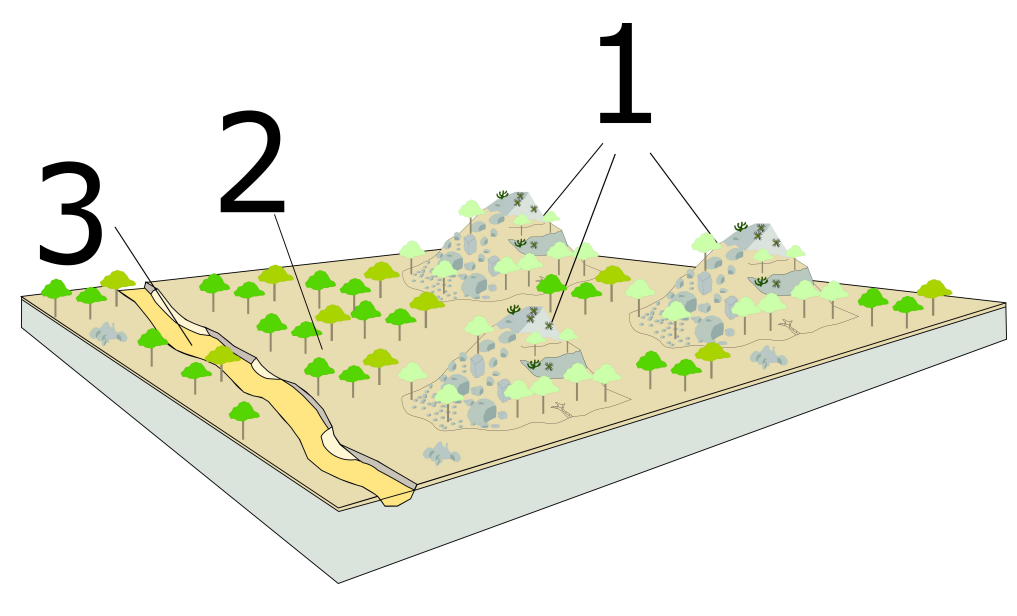

Figura 3. Paisagem (macrogeócoro) de pedimentos com inselbergs. 1 - Trato de inselberg com Anadenanthera colubrina com cactos e bromélias em lajedos; 2 - Trato de Pedimento com Mimosa e Poincianella; 3 - Trato de canal fluvial intermitente. Fonte: os autores.

Uma paisagem ainda pode apresentar, em sua estrutura morfológica, unidades intermediárias formadas pelo agrupamento de Tratos. Um exemplo é a Localidade (Mesogeócoro ou Mestnost - местност). As Localidades se caracterizam por oferecer, dentro de uma mesma Paisagem, condições distintas para a formação de Tratos. Geralmente isso se dá em função de variações no litótipo bem como a presença de condicionantes sobre os padrões de drenagem.

Na proposta de Solntcev, a estrutura morfológica da Paisagem é composta de Localidades, Tratos, Subtratos e Fácies agrupadas hierarquicamente. Contudo, as paisagens ainda estão contidas em diversas subunidades do Envelope Geográfico da Terra, que foram sistematicamente organizadas por A.G. Isachenko $(1973,1991)$, sendo denominadas de unidades regionais.

Cabe salientar que a rigidez de ocorrência das unidades descritas acima tem sido questionada para muitas áreas, que aparentam ter uma hierarquia de unidades ora mais simples, ora mais complexa em função do contexto ambiental. Para discussões específicas sobre essa questão ver Khoroshev; Merekalova; Aleschenko (2007), Mamay (2007), Chernykh e Zolotov (2007), Cavalcanti; Corrêa (2013); Cavalcanti (2014).

As variações e ausência de consenso entre as diferentes sínteses em diferentes áreas sugerem que essa distinção entre a quantidade de níveis hierárquicos e os modos de identificá-los possa estar relacionada a uma adaptação de tais esquemas classificatórios à realidade das paisagens locais, como nos indica Monteiro (2000).

Diferentemente do agrupamento utilizado para identificar as unidades da estrutura morfológica da paisagem (fácies, tratos, etc.), as unidades de dimensões meso, macro e megarregionais são diferenciadas a partir de uma divisão lógica do Envelope Geográfico da Terra, divisão esta que se baseia em fatores bioclimáticos (denominados zonais) e geológico-geomorfológicos (denominados azonais) (ISACHENKO, 1991).

Em princípio, na proposta taxonômica de A.G. Isachenko, diferenciam-se unidades e subunidades geradas por condicionantes cósmicos e atmosféricos (zonais), tal como faixas com mes- 
mo clima regional; em seguida, diferenciam-se unidades e subunidades naturais formadas por processos geológico-geomorfológicos (azonais), tal como morfoestruturas com diferentes dimensões; Por fim, ambos os conjuntos são correlacionados de modo a se obter unidades e subunidades derivadas, correspondendo aos geossistemas regionais.

No desenvolvimento de sua sistemática, Isachenko (1991) propõe unidades e subunidades geradas por processos cósmicos e/ou atmosféricos (Zonais) compreendem as seguintes categorias: Cinturão (пояс), Zona (зона), Subzona (подзона). As unidades e subunidades decorrentes de processos geológico-geomorfológicos (Azonais) são: Continente (континент), Subcontinente (субконтинент), País (страна), Domínio (область) e Subdomínio (подобласть). Além destas, inclui-se uma categoria de unidades azonais definidas pelo efeito da continentalidade que, às vezes substituem as unidades Zonais, denominadas Setor (сектор) e Subsetor (подсектор). A Figura 4 sumariza as características de cada categoria de unidades bem como os elementos necessários e/ou auxiliares à sua identificação.

O cruzamento das unidades zonais e azonais permite classificar geossistemas regionais, que apresentam as seguintes categorias: Província (провинция), Subprovíncia (подпровинция), Distrito (округ), Subdistrito (подокруг). Detalhes da classificação regional de Isachenko (1991) já foram apresentados por Cavalcanti (2010) e Cavalcanti, Corrêa e Araújo Filho (2011).

Cada uma destas áreas naturais identificadas foi chamada de indivíduo geográfico. Todavia, foi percebido por Nikolai A. Solntcev que, numa mesma região é possível que existam indivíduos com características muito similares, sobretudo nos níveis hierárquicos de menor ordem (fácies, tratos, localidades, etc.) a partir disso ele propôs, para poupar esforço, que os mapas apresentassem não os indivíduos, mas sim seus tipos (ISACHENKO, 1973), estes tipos foram chamados por Sochava de geômeros (cf. tópico 5).

O menor geômero seria uma fácies ou biogeocenose (ver acima). Diferentes áreas possuindo as mesmas associações de fácies, permitiram ser agrupadas em grupos de fácies. Nos exemplos das figuras 2 e 3, percebe-se que os geócoros la e lb se repetem em diferentes inselbergs. Isto significa que, funcionalmente são semelhantes, por isso, mesmo possuindo localizações diferentes, pertencem ao mesmo tipo de associação funcional - grupo de fácies.

Grupos de fácies podem ser agrupados em classes de fácies. No caso do exemplo da figura 3, os diferentes inselbergs podem ser agrupados numa única classe de fácies: Inselbergs com Anadenanthera colubrina, bromélias e cactos.

Foi baseada nesta noção de unidades físico-geográficas que a análise genético-estrutural da paisagem já havia se consolidado na Rússia na metade do século passado. Contudo, muito pouco havia sido feito no sentido de uma abordagem integrada sobre a dinâmica e evolução das paisagens, sendo esta a grande contribuição de Viktor B. Sochava.

A adoção da linguagem sistêmica aplicada à ideia de paisagens permitiu a Sochava resolver alguns entraves da geografia física soviética através da formulação da Teoria dos geossistemas. Um exemplo foi a diferenciação disciplinar que existia entre a ciência da paisagem e a regionalização físico geográfica, que após Sochava passaram a fazer parte do Estudo de Geossistemas, diferenciando-se apenas a escala dos fenômenos considerados.

Além disso, só a partir da fusão da teoria dos sistemas com a compreensão realista de á- 
reas naturais (paisagens) da geografia russo-soviética, realizada por Sochava, é que a ciência da paisagem pôde crescer não apenas sobre a análise espacial, mas também sobre uma compreensão temporal dos geossistemas (Cf. tópicos a seguir sobre as dimensões espaciais e temporais dos geossistemas).

\section{Como a interpretação sistêmica se presta a uma teoria das paisagens?}

Nos países influenciados pela geografia da antiga URSS, é consenso que a proposta de Sochava trouxe um avanço na compreensão integrativa dos fenômenos espaciais e temporais que formam as paisagens, bem como num esclarecimento das dimensões epistemológicas da própria geografia física em sua versão integrada. Foi, pois, a introdução da palavra geossistema, na literatura geográfica soviética, que representou uma revolução conceitual e metodológica para a geografia física.

Revolução conceitual porque a partir da incorporação da visão sistêmica, princípios de sistemas dinâmicos (ex.: fases, equilíbrio), da cibernética (ex.: retroalimentação), da complexidade (trocas de energia e matéria com o entorno), entre outros, passaram a ser aplicados à análise da paisagem. Isto facilitou a integração entre informações provenientes de áreas distintas, alargando o horizonte epistemológico da análise da paisagem.

Não obstante, o tratamento das unidades de paisagem como complexos dinâmicos, abertos e hierarquicamente organizados, demandou mudanças metodológicas no sentido de abarcar a demanda por uma compreensão integrada das paisagens. Neste sentido, a geografia física integrada, como Ciência da Terra, passa a estar circunscrita dentro de quatro enfoques ou direcionamentos de pesquisa principais: genético-estrutural, dinâmico-funcional, evolutivo e antropogênico.

O enfoque genético-evolutivo trata da investigação da expressão espacial resultante das interações entre elementos e processos que compõem a superfície da Terra. A estrutura da paisagem é, pois, representada por conjuntos de relevo, drenagem, solos e biota, sob um mesmo clima e estrutura geológica. A cartografia das paisagens é um dos métodos fundamentais aplicados para este fim. Este é o enfoque tradicional, mas não menos importante, da análise da paisagem que, a partir da teoria dos sistemas, passa a integrar, principalmente a preocupação com a dimensão temporal das paisagens. A vegetação e os solos, por exemplo, passam a ser compreendidos como estados vegetacionais e estados pedológicos, revelando a consideração da paisagem dentro de uma trajetória e não apenas como um quadro de natureza.

O enfoque dinâmico-funcional consiste na investigação de regularidades no funcionamento dos geossistemas, resultantes da transformação da matéria e energia pelos geossistemas. Isto é realizado determinando-se as entradas e saídas de radiação solar, água, nutrientes, sedimentos e sua transformação pelos diferentes componentes do geossistema.

A proposta de Sochava para os estudos dinâmico-evolutivos, envolve o estabelecimento de estações de pesquisa permanente, coletando dados meteorológicos, biogeoquímicos e outros com o objetivo de responder questões do tipo: como diferentes geossistemas respondem à sazo- 
nalidade do balanço de radiação? As respostas são avaliadas em função do balanço hídrico, de nutrientes, fenologia, produtividade primária, decomposição de matéria orgânica, etc.

Não obstante, o monitoramento permanente de geossistemas permite não apenas definir as realimentações e ritmos sazonais na transformação da matéria e da energia, como também avaliar o efeito das mudanças climáticas sobre a resposta de cada geossistema em termos hidrológicos, biológicos e biogeoquímicos.

O enfoque evolutivo trata das mudanças nos geossistemas, investigando diferentes fases nos geossistemas, determinando momentos de estabilidade e de ruptura do equilíbrio ambiental a partir da reconstrução de paleogeossistemas. Este enfoque trabalha em duas frentes principais, uma delas é a reconstrução de momentos de estabilidade do espaço de fase dos geossistemas, indicada pelos registros botânicos (pólen, fitólitos, anéis de crescimento, etc.), paleossolos e transformação da cobertura pedológica (micromorfologia de solos), biogeografia, dados paleoclimáticos (ex.: estalactites), paleofauna, entre outros.

A outra frente de trabalho busca determinar rupturas na estabilidade ambiental, definindo mudanças no espaço de fase, representadas principalmente por pulsos na produção de sedimentos. Os dados são oriundos da geomorfologia do Quaternário, morfoestratigrafia, geocronologia, morfotectônica, assinatura geoquímica e outras fontes similares. A integração dos dados dos momentos de estabilidade e de ruptura desta, permite a reconstrução do espaço de fase, isto é, da trajetória das mudanças (desenvolvimento) ocorridas nos geossistemas ao longo do tempo.

O enfoque antropogênico lida com as derivações na estrutura e funcionamento dos geossistemas decorrente do aumento na entropia dos sistemas em função das atividades da sociedade. Este enfoque desenvolve-se pela avaliação e previsão de impactos ambientais, a avaliação de risco de desastres naturais, do potencial e limitações de uso dos geossistemas. Nesta linha o objetivo é definir mudanças nos componentes e taxas de operação de processos naturais em função de atividades econômicas e de uso da terra no geral.

A partir da perspectiva sistêmica a análise da paisagem passa a integrar métodos e temas diversos para compreender o funcionamento conjunto dos sistemas ambientais e seu comportamento diante da interação com a sociedade. Isto é realizado a partir dos diferentes direcionamentos que, juntos, permitem uma explicação integrada da paisagem, revelando sua estrutura, origem, funcionamento e mudanças, seja por causas naturais ou pela intervenção da sociedade. Deste modo, a teoria dos geossistemas, enquanto teoria da paisagem, é uma ferramenta poderosa para o estreitamento do diálogo entre as diferentes áreas da geografia física.

\section{Dimensão espacial dos geossistemas}

O geossistema em Sochava é compreendido como uma unidade natural dinâmica de qualquer dimensão, da maior dimensão espaço-temporal (toda a superfície terrestre), à menor (ex.: um pequeno setor morfodinâmico de encosta com mesmo sistema de transformação pedológica e estágio de sucessão florestal). Nestes termos, a definição do russo é completamente diferente daquela 
que Bertrand propõe em 1968, para o seu modelo de Geografia Física Global, uma vez que para Sochava os geossistemas podem possuir qualquer dimensão (de alguns metros até toda superfície terrestre), enquanto para o francês, os geossistemas são da ordem das dezenas às centenas de quilômetros quadrados.

Em seu livro Introdução à Teoria dos geossistemas, Sochava (1978, pp. 101-102) chega a comentar a diferença entre sua proposta e a de Bertrand, expondo que existe uma divergência escalar na acepção do termo. Assim, eles divergem em termos da abrangência espacial dos geossistemas, sendo a conceituação do geógrafo francês um pouco mais restrita (como vimos acima) e a do russo mais geral e abrangente, como veremos a seguir. Segundo o geógrafo russo, o geossistema de Bertrand seria o seu macrogeócoro.

Contudo, como foi visto, Bertrand abre mão de sua definição anterior e abraça a concepção soviética, na qual se baseia para formular seu modelo de análise integrada das relações entre sociedade e natureza, a partir das relações entre os geossistemas, o território e a paisagem (o modelo GTP).

Com base na compreensão destas diferenças, se torna mais fácil apreender uma série de desentendimentos conceituais que ocorrem na literatura geográfica brasileira em função, sobretudo, do não conhecimento do artigo de Beroutchachvili e Bertrand, de 1978, onde o geógrafo francês explicitamente abre mão de sua definição inicial para propor algo mais abrangente. A seguir vamos avaliar e tentar esclarecer algumas dessas confusões conceituais, começando pela compreensão das dimensões espaço-temporais dos geossistemas.

Um primeiro problema que encontramos na interpretação da ideia de geossistemas no Brasil é quando se estende a definição de Bertrand em 1968, ao trabalho de Sochava e tenta-se compreender o trabalho do geógrafo russo em função de partilhar o mesmo termo que o do francês. Isso definitivamente não funciona, porque, como vimos, apesar de usarem o mesmo termo (geossistema), Bertrand em 68 e Sochava referem-se a coisas distintas.

Além disso, o não esclarecimento, por parte de Sochava, nos únicos dois textos seus que foram traduzidos para o português, de termos como geômeros e geócoros, somado ao já referido desconhecimento do artigo de Beroutchachvili e Bertrand (1978), em francês, conduziu a erros interpretativos sobre a dimensão dos geossistemas em Sochava.

Assim, alguns autores brasileiros tenderam a interpretar a proposta de Sochava pela de Bertrand, a exemplo de Troppmair e Galina (2006, p.81) que, baseados na ideia de que a antiga URSS seria um país de dimensões continentais, afirmam ter concluído que o geógrafo russo se referia a áreas de dimensões subcontinentais (tundra, estepes, etc.), quando utilizava o termo geossistema, o que, definitivamente, não é coerente com as escalas que Sochava propõe para cartografia de fácies (1:5.000), chegando a sugerir a elaboração de mapas nas escalas 1:500 e 1:350 para estudar o funcionamento dos geossistemas locais e suas trocas de matéria e energia com os geossistemas adjacentes em transectos com 1,5km (SOCHAVA, 1978; KRAUKLIS, 1979).

É neste sentido que sempre se tratou a ideia de geossistema na geografia brasileira, na perspectiva das definições dadas por Bertrand em seu artigo de 1968, mais do que pela perspectiva de outros autores como Sochava, por exemplo, o que gera uma compreensão bastante distin- 
ta sobre a teoria em questão (Cf. MONTEIRO, 1976; 2000; AB'SÁBER, 2003; VICENTE \& PEREZ FILHO, 2003, NASCIMENTO \& SAMPAIO, 2005).

De outro modo, Sales (2004, p.128-129) afirma que a perspectiva geossistêmica desconsidera a dimensão temporal dos processos naturais, no sentido de que ignora escalas e processos evolutivos de ordem morfoestrutural. Além disso, a autora resume muitas das abordagens que se dizem "geossistêmicas" à simples agrupamentos de informações temáticas sobre o meio ambiente (cf. Sales, op. cit., p.131). Deste modo, a autora emite uma opinião crítica sobre aquilo que, na maioria das vezes, foi feito da abordagem geossistêmica no Brasil, ou seja, simples complicação terminológica. Todavia, uma compreensão mais ampla da ideia de geossistema, permite um entendimento distinto daquele da autora sobre a dimensão temporal dos geossistemas (cf. tópico 7, mais adiante).

Além da confusão sobre a dimensão espacial dos geossistemas, o espectro terminológico relacionado às propostas de Bertrand e Sochava também pode levar a interpretações errôneas. Um exemplo é a concepção associada aos termos geofácies, geótopos, geócoros, geômeros, entre outros, como veremos a seguir.

\section{Geofácies, geótopos e tantos outros termos}

De forma similar à diferença conceitual entre o termo geossistema em Bertrand e em Sochava, os termos geofácies e geótopo também possuem conotações ambíguas na literatura geográfica, enquanto os termos geócoro e geômero são bastante peculiares aos trabalhos desenvolvidos pelo antigo Instituto de Geografia da Sibéria (hoje Instituto Viktor Sochava de Geografia).

O termo geofácies é referido inicialmente por Bertrand (1968) como uma subdivisão espacial do geossistema. Assim, os geossistemas seriam unidades da $4^{\mathrm{a}}$ ou $5^{\mathrm{a}}$ ordem de grandeza, enquanto os geofácies seriam da $6^{\mathrm{a}}$ ordem. Igualmente, os geótopos seriam subdivisões dos geofácies manifestando-se na $7^{\mathrm{a}}$ ordem de grandeza de Cailleux e Tricart.

Em Beroutchachvili e Bertrand (1978), quando o geógrafo francês adota uma nova concepção, o termo geofácies aparece em outra acepção, sinônima ao conceito de fácies de Sochava, sendo definido como uma associação de geohorizontes. Assim, o geofácies da proposta de Bertrand em 1968, antes da $6^{\mathrm{a}}$ ordem de grandeza, dez anos depois se torna sinônimo do que antes era chamado de geótopo. Esta mudança de concepção do geógrafo francês foi acompanhada também por uma mudança terminológica que, em alguns casos, inverteu o significado atribuído à uma determinada palavra, no caso, geofácies.

Já o termo geohorizonte foi introduzido por Nikolai Beruchashvili para descrever os diferentes componentes da estrutura vertical de uma fácies. Assim, o geohorizonte é descrito em termos das associações das diferentes substancias, que implica o uso do termo geomassa, que é aplicado para definir a ideia de matéria geográfica, ou seja, aquela que pode ser agrupada conforme sua posição entre as esferas geográficas, a saber: litosfera (litomassa), atmosfera (aeromassa), hidrosfera (hidromassa), biosfera (biomassa) (BERUCHASHVILI, 1986). 
Além disso, a geomassa pode ser subdividida em pedomassa, fitomassa, zoomassa, necromassa, etc. (ISACHENKO, 1998; EGOROV, 2008). Assim, um geohorizonte seria um estrato da paisagem onde houvesse a mesma combinação de geomassa, isto é, a diferenciação não estaria relacionada apenas à sequência de estratos vegetais e dos horizontes do solo, pois também deveria incluir as condições da hidrosfera e atmosfera.

Como exemplo de geofácies na concepção de Beroutchachvili e Bertrand (1978) podemos apresentar o caso observado no semiárido brasileiro (CAVALCANTI, 2010; CAVALCANTI et al., 2010), no município de Poço das Trincheiras (Alagoas) (Fig. 4). Observando um segmento de encosta com aproximadamente $20 \mathrm{~m}^{2}$, foi elaborado um perfil de geofácies contendo os seguintes geohorizontes (descritos de cima para baixo): I - Atmosfera sem interferência da vegetação com limite em 3 metros. II - Folhas anuais de árvores e arbustos em queda, lianas e limite inferior em 1,7 metros. III - Rocha aflorante, Folhas anuais de árvores e arbustos em queda, transporte de biosubstâncias, líquens nos troncos das árvores e em algumas rochas, lianas e limite em 0,3 metros. IV - Rocha aflorante, Transporte de biosubstâncias, presença de lianas, folhas e caules de herbáceas com limite de 0,1 metro. V - Rocha aflorante, Transporte de biosubstâncias, presença de lianas, folhas e caules de herbáceas, Serrapilheira não destruída, limite na linha de superfície. VI - Rocha e cascalho, raízes e umidade insuficiente com limite de profundidade em $30 \mathrm{~cm}$. VII Rocha com limite de profundidade desconhecido.

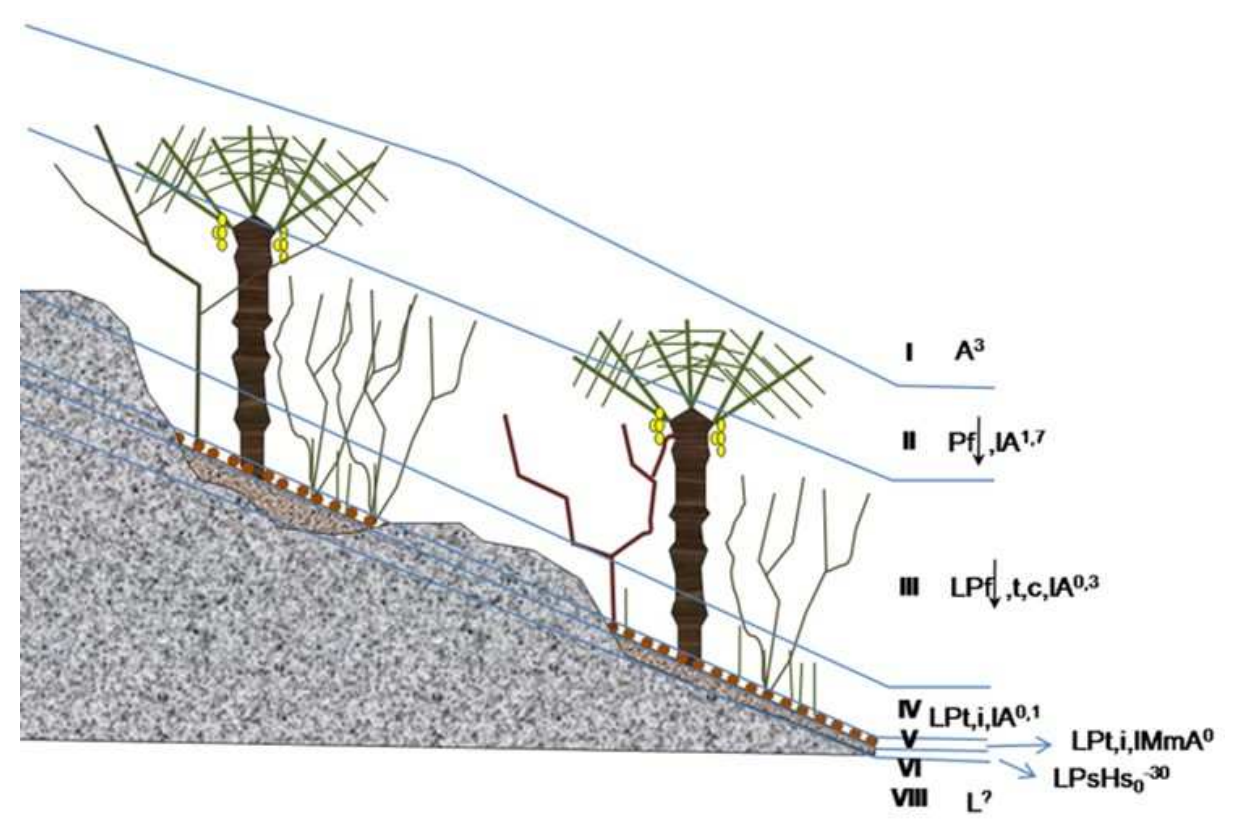

Figura 4. Geofácies, geohorizontes e distribuição da geomassa. A - Aeromassa, P - Fitomassa, L - Litomassa, H Hidromassa, M - Necromassa. As letras minúsculas representam variações da geomassa. Os números indicam a altura/profundidade do geohorizonte. Fonte: CAVALCANTI (2010); CAVALCANTI et al. (2010).

Considerando toda esta variabilidade de terminologias e acepções intercambiantes e ainda, para evitar maiores confusões, elaborou-se um quadro de correlação entre os termos utilizados por Bertrand, Sochava e Bertrand e Beroutchachvili (Quadro 1). Espera-se que o quadro colabore 
para solucionar dúvidas e auxiliar o entendimento sobre a natureza distinta das propostas apresentadas.

Quadro 1. Correspondência de termos em Bertrand e Sochava.

\begin{tabular}{|c|c|c|c|}
\hline Termo & Bertrand (1968) & $\begin{array}{c}\text { Beroutchachvili \& } \\
\text { Bertrand (1978) }\end{array}$ & Sochava (1978) \\
\hline Geócoro & Não utilizado & Não utilizado & $\begin{array}{c}\text { Associação funcional } \\
\text { de geossistemas }\end{array}$ \\
\hline Geofácies & $\begin{array}{l}\text { Subdivisão dos Geos- } \\
\text { sistemas da } 6^{\mathrm{a}} \text { ordem } \\
\text { de grandeza }\end{array}$ & $\begin{array}{l}\text { Utilizado como sinônimo } \\
\text { de fácies. Unidade com } \\
\text { mesma associação de } \\
\text { geohorizontes. } 7^{a} \text { ordem } \\
\text { de grandeza }\end{array}$ & Não utilizado \\
\hline Geohorizonte & Não utilizado & Estrato de um geofácies & Não utilizado \\
\hline Geomassa & Não utilizado & $\begin{array}{l}\text { Qualquer tipo de matéria } \\
\text { componente da paisagem }\end{array}$ & Não utilizado \\
\hline Geômero & Não utilizado & Não utilizado & $\begin{array}{l}\text { Tipo de geossistema } \\
\text { Termo genérico que }\end{array}$ \\
\hline Geótopo & $\begin{array}{c}\text { Subdivisão dos Geofá- } \\
\text { cies da } 7^{\mathrm{a}} \text { ordem de } \\
\text { grandeza }\end{array}$ & Não utilizado & $\begin{array}{c}\text { se refere a qualquer } \\
\text { ordem de geossiste- } \\
\text { mas locais }\left(4^{\mathrm{a}}, 5^{\mathrm{a}}, 6^{\mathrm{a}}\right. \\
\text { e } 7^{\mathrm{a}} \text { ordens de gran- } \\
\text { deza) }\end{array}$ \\
\hline
\end{tabular}

Fonte: Bertrand (1968); Beroutchachvili e Bertrand (1978); Sochava (1978). Organizado pelos autores.

É importante destacar que o geógrafo russo prefere o uso das palavras fácies físicogeográfica ou simplesmente fácies em detrimento de geofácies (SOCHAVA, 1963; 1977; 1978). Em termos comparativos, a fácies de Sochava é o geótopo de Bertrand em 1968/1971 e o geofácies de Beroutchachvili e Bertrand em 1978, abrangendo uma unidade físico-geográfica da $7^{\mathrm{a}}$ ordem de grandeza.

Quanto ao termo geótopo, em Sochava, este é associado a qualquer dos geossistemas locais (localidades, tratos, subtratos, fácies) e seu estudo é denominado geotopologia, em contraponto à regionalização físico-geográfica, que se preocupa com os geossistemas regionais e globais. Deste modo, o geótopo para o geógrafo russo não representa uma unidade natural com dimensão determinada, mas um termo genérico para designar geossistemas de pequenas dimensões.

Sochava ainda propõe mais termos como geômeros, geócoros, epigeômeros e outros. Contudo, os termos geócoro e geômero, possuem uma definição bastante simples, mas cuja tradução não foi realizada em idioma português, dificultando sua compreensão, por exemplo, Nascimento e Sampaio (2005, p. 174) acreditam que é um problema aplicar a ideia de geossistema em função de os geômeros estarem relacionados às escalas das zonas climáticas, enquanto os geócoros possuírem escala regional, quando na verdade os conceitos relacionam-se a duas formas de organização da informação, de tipologia e de regionalização, respectivamente, ambos abrangendo as escalas local, regional e planetária (SOCHAVA, 1978; ISACHENKO, 1991). 
Neste contexto, o termo regionalização é utilizado para diferenciar unidades naturais, independentemente de sua dimensão espacial (local, regional, planetária), enquanto o termo tipologia é associado aos tipos de unidades. Assim, os geócoros são unidades naturais de qualquer dimensão, identificadas individualmente (ex.: o inselberg da Serra da Santa em Petrolina), enquanto os geômeros são tipos de unidades naturais (ex.: Inselbergs com caatinga arbórea de Anadenanthera colubrina). No exemplo dado, a Serra da Santa (em Petrolina-PE) constitui um geócoro (especificamente um microgeócoro), que partilha características com outros inselbergs vizinhos, como a presença dominante da leguminosa angico-de-caroço (Anadenanthera colubrina), fazendo parte de um geômero (especificamente uma classe de fácies).

Apesar de toda inovação terminológica trazida por Sochava, muitos dos conceitos já apresentavam definição bem claras na geografia russo-soviética. De acordo com Mamay (2007), as aproximações regionais e tipológicas já haviam sido desenvolvidas por Lev S. Berg antes do final da década de 1940.

Neste sentido, deve-se ressaltar que a geografia soviética, à época em que Sochava promove o desenvolvimento da epígrafe 'geossistema' (décadas de 1960 e 1970) já apresentava direcionamentos bastante consolidados na discussão sobre uma teoria de áreas naturais, compreendendo a fácies, o envelope geográfico e toda a gama de unidades intermediárias como entidades reais.

Em 1965, A.G. Isachenko lança o primeiro livro dedicado inteiramente ao tema, intitulado "Princípios de Ciência da Paisagem e Regionalização Físico-Geográfica", com versão em inglês de 1973. Neste livro o autor divide a Geografia Física Integrada em duas disciplinas: Ciência da Paisagem que busca o estudo das unidades de dimensões locais $\left(<10^{2} \mathrm{~km}^{2}\right)$, que é sinônima à Geotopologia de Sochava e; a Regionalização Físico-Geográfica tratando do estudo de unidades superiores a $10^{2} \mathrm{~km}^{2}$ (grosseiramente falando).

Em 1991, A.G. Isachenko publica uma segunda edição de seu livro (sem tradução para inglês) e revisa as denominações aplicadas aos geossistemas de diferentes dimensões pelos autores soviéticos e verifica a recorrência de algumas terminologias, a partir dos quais é possível diferenciar um conjunto de unidades taxonômicas largamente aceitas, entre os geógrafos russosoviéticos, a saber: epigeosfera (эпигеоссрера), cinturão (пояс), zona (зона), subzona (подзона), setor (сектор), subsetor (подсектор), continente (континент), subcontinente (субконтинент), domínio (область), subdomínio (подобласть), província (провинция), subprovíncia (подпровинция), distrito (округ), subdistrito (подокруг), paisagem (ландшаст), terreno (местност), trato (урочище), subtrato (подурочище) e fácies (фрация).

A proposta taxonômica de Sochava (1978) apresenta uma nomenclatura bem particular para as unidades naturais (geossistemas), mas que não se afastam grandemente daquelas citadas acima. Na sua proposta, o referido geógrafo apresenta categorias e ordens de geossistemas, correspondendo aos geômeros e geócoros, respectivamente (Quadro 2).

Foi levando em conta a inserção real dos geócoros de níveis mais baixos naqueles de níveis mais elevados que Sochava (1978) se refere a eles como possuindo diferentes ordens, classificando-os em microgeócoros (sinônimo de Tratos), mesogeócoros (sinônimo de Localidades), macrogeócoros (sinônimo de Paisagens) etc. 
Quadro 2. Subdivisão taxo-corológica dos geossistemas.

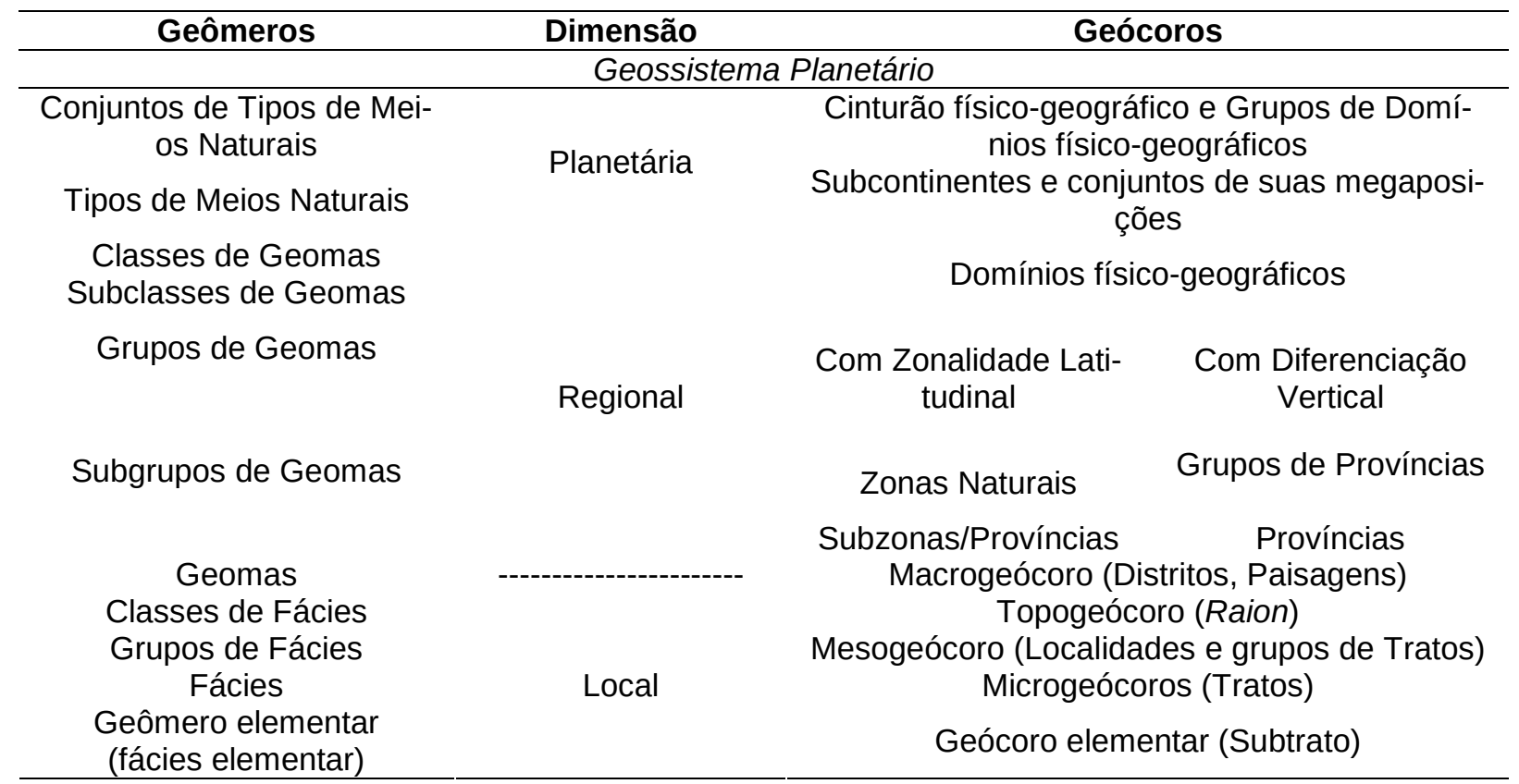

Fonte: Sochava, 1978, p.92; Cherkashin, 2011. Modificado pelos autores.

Não obstante, sendo os geômeros correspondentes a diferentes tipos de unidades, eles são referidos como possuindo diferentes categorias definidas pela generalização tipológica das fácies, assim tem-se: grupos de fácies, classes de fácies, geomas (agrupamento de classes de fácies), subgrupos de geomas, grupos de geomas e assim por diante.

As diferentes categorias de geômeros seriam determinadas com base em algum atributo que reflita sua natureza similar de um conjunto de geócoros. Dando exemplos de geômeros de dimensões planetária e regional, Sochava (1978, p.94) propõe um Cinturão de Paisagens Extratropicais Setentrionais que contém a Taiga. Esta, por sua vez, distribui-se sobre as Planícies e Montanhas Euroasiáticas, que constituem Classes de Geomas (Quadro 3).

O conceito de geoma, em Sochava, consiste numa representação tipológica mesorregional, constituída por um agrupamento de classes de fácies com atributos estruturais e dinâmicos similares, que pode ser representado pelo tipo de vegetação regional e sua posição morfoestrutural, por exemplo.

Os geócoros de diferentes ordens são nomeados a partir de elementos físico-geográficos de destaque para a área estudada. No caso da Ásia Setentrional, Sochava (1978, p.99) diferencia dois critérios para regionalização de domínios físico-geográficos, aqueles condicionados pela distribuição latitudinal da radiação e gradientes termo-hídricos e os que se definem pelo gradiente hipsométrico. No primeiro caso, o autor destaca o domínio das planícies drenadas pelos rios Ob e Irtysh e; no segundo caso, os domínios montanhosos de Baikal a Dzhugdzhursky (Quadro 4). 
Quadro 3. Exemplos de geômeros planetários e regionais.

\begin{tabular}{|c|c|c|}
\hline Categorias de Geômeros & \multicolumn{2}{|c|}{ Exemplos } \\
\hline $\begin{array}{c}\text { Conjuntos de Tipos de } \\
\text { Meios Naturais }\end{array}$ & \multicolumn{2}{|c|}{ Cinturão de Paisagens Boreais Intertropicais } \\
\hline Tipos de Meios Naturais & \multicolumn{2}{|l|}{ Taiga } \\
\hline $\begin{array}{l}\text { Classes de Geomas } \\
\text { Subclasses de Geomas }\end{array}$ & $\begin{array}{l}\text { Planícies Euroasiáticas } \\
\text { Ob-Irtysh }\end{array}$ & $\begin{array}{c}\text { Montanhas Euroasiáticas } \\
\text { Baikal-Dzhugdzhursky }\end{array}$ \\
\hline Grupos de Geomas & Taiga Escura de Ob-Irtysh & $\begin{array}{l}\text { Taiga Decidual de Baikal- } \\
\text { Dzhugdzhursky }\end{array}$ \\
\hline Subgrupos de Geomas & $\begin{array}{l}\text { Geomas da Taiga Escura Meridio- } \\
\text { nal de Ob-Irtysh }\end{array}$ & $\begin{array}{l}\text { Geomas da Taiga Deci- } \\
\text { dual Montana Otimamen- } \\
\text { te Desenvolvida }\end{array}$ \\
\hline Geomas & Taiga de Picea abies das Planícies & $\begin{array}{l}\text { 1. Taiga Decidual de Ba- } \\
\text { cia Intra-Montana } \\
\text { 2. Taiga Decidual de En- } \\
\text { costa }\end{array}$ \\
\hline
\end{tabular}

Fonte: Sochava, 1978, p. 94. Organizado pelos autores.

Quadro 4. Outros exemplos de geômeros planetários e regionais.

\begin{tabular}{|c|c|c|c|c|}
\hline \multirow[b]{2}{*}{ Planetária } & \multicolumn{2}{|c|}{ Ordens de Geócoros } & \multicolumn{2}{|r|}{ Exemplos } \\
\hline & \multicolumn{2}{|c|}{$\begin{array}{c}\text { Cinturão físico-geográfico } \\
\text { Grupos de Domínios físico-geográficos } \\
\text { Subcontinentes } \\
\text { Domínio físico-geográfico }\end{array}$} & \multicolumn{2}{|c|}{$\begin{array}{c}\text { Cinturão Extratropical Setentrional } \\
\text { Ártico Boreal } \\
\text { Ásia Setentrional }\end{array}$} \\
\hline \multirow{2}{*}{ Regional } & $\begin{array}{l}\text { Com Zonalidade } \\
\text { Latitudinal } \\
\text { Zonas Naturais }\end{array}$ & $\begin{array}{l}\text { Com Diferenciação } \\
\text { Vertical } \\
\text { Grupos de Provín- } \\
\text { cias }\end{array}$ & Ob-Irtysh & Baikal-Dzhugdzhursky \\
\hline & $\begin{array}{l}\text { Subzo- } \\
\text { nas/Províncias }\end{array}$ & Províncias & $\begin{array}{l}\text { Taiga Cen- } \\
\text { tral/Yenisey }\end{array}$ & $\begin{array}{l}\text { Taiga ao Oeste de } \\
\text { Transbaikal em Áreas } \\
\text { Rochosas de Cimeira }\end{array}$ \\
\hline Local & \multicolumn{2}{|c|}{ Macrogeócoro (Distrito) } & $\begin{array}{c}\text { Taiga Escura das } \\
\text { Planícies sinuosas } \\
\text { de Chulym }\end{array}$ & $\begin{array}{c}\text { Cimeira Rochosa de } \\
\text { Preangara }\end{array}$ \\
\hline
\end{tabular}

Fonte: Sochava, 1978, p. 99. Organizado pelos autores.

Nota-se que a proposta de Sochava destoa ligeiramente daquela de Isachenko, sobretudo no tocante à identificação das unidades de dimensões regionais. O primeiro autor, por exemplo, não faz referência a unidades derivadas do cruzamento de elementos zonais e azonais. Assim, percebe-se que, apesar de haver certo consenso acerca das unidades físico-geográficas existentes, o modo de agrupar a informação difere largamente.

De forma a complementar e auxiliar a diferenciação (regionalização) das unidades físicogeográficas, também se propõe a classificação destas unidades, ou seja, o agrupamento de unidades semelhantes em tipos, caracterizando uma tipologia, também chamada taxonomia. Aqui vamos destacar algumas das propostas taxonômicas comuns à geografia russo-soviética. 
Na proposta taxonômica de Isachenko (1991) e também no seu mapa de paisagens do mundo (ISACHENKO; SHLIAPNIKOV, 1989), é apresentada uma sistemática que enquadra as diferenças paisagísticas numa série de categorias, a saber:

- Tipo: definidos pelo caráter geral do funcionamento hidrotérmico, com base em índices derivados de elementos climáticos (temperatura, precipitação, etc.), como o índice de umidade, o índice de continentalidade e a soma das temperaturas ativas;

- Subtipo: definidos com base em pequenos contrastes no interior dos tipos;

- Classe: inclui duas classes: montanhas e planícies;

- Subclasse: inclui partes de planícies e montanhas. Para as planícies existem duas subclasses: terras baixas e terras altas. Para as montanhas existem três subclasses: submontana, montana e alto montana.

- Espécie: inclui áreas com máxima similaridade em termos de gênese, componentes característicos (relevo, solos, vegetação, etc.) e estrutura morfológica.

No livro 'Mundo Natural: Paisagens' Isachenko e Shliapnikov (1989) determinam tipos, subtipos, classes e subclasses das paisagens do mundo, mas apresentam as espécies congregadas em pouco mais de 600 grupos.

Na proposta de Vladimir A. Nikolaev (1979), da Universidade Estatal de Moscou, são apresentadas sete categorias, saber:

- Divisão: tipo de contato e interação entre as esferas geográficas com a esfera da paisagem (divisão de paisagens terrestres, paisagens aquáticas, etc.);

- Sistema: base energética das paisagens - distinções zonais dos balanços de água e calor (sistemas de paisagens subárticas, paisagens boreais, etc.). Pode ser dividido em subsistemas de acordo com o grau de continentalidade;

- Família: Localização regional no país físico-geográfico (Boreal temperado continental Europa Setentrional);

- Classe: morfoestruturas de alta ordem (elementos do megarrelevo), tipo de zonalidade natural - vertical ou horizontal (classes de paisagens planas e montanhosas). Pode ser dividido em subclasses de acordo com diferenças internas do megarrelevo;

- Tipo: características dos solos e vegetação no nível de tipos de solos e classes de formação de plantas (tipos zonais de paisagens; tundras, tundras florestais, etc.). Pode ser dividido em subtipos;

- Gênero: tipos genéticos de relevo (denudacional, lacustre, fluvial, etc.). Pode ser dividido em subgêneros de acordo com a litologia superficial (argila, areia, cascalho, etc.);

- Espécie: similaridade dos Tratos predominantes nas Paisagens. Pode ser dividido em subespécies.

Estudando a região do Cáucaso, o georgiano Nikolai L. Beruchashvili (1989) também propôs um sistema para taxonomia da paisagem, preferindo o termo 'Complexos Territoriais Naturais', de Dokuchaev. Atualmente, esta proposta serve de referência para a determinação do funcionamento das paisagens da Geórgia, baseada na determinação dos Stexe (ver mais adiante) para a categoria dos gêneros (ver abaixo).

- Classe: envolve duas classes: Montanhas e Planícies;

- Subclasses: Sub-Montana, Montana, Alto Montana, Terras Altas e Terras Baixas; 
- Tipo: usualmente é baseada principalmente em atributos hidrometeorológicos, considerando também atributos gerais da estrutura, migração de elementos químicos, parâmetros biológicos e etc.;

- Subtipo: é determinado de acordo com diferenças identificadas dentro de um mesmo tipo;

- Gênero: determinado de acordo os seguintes atributos:

o Tipo de relevo dominante (erosivo, acumulativo, etc.);

- Litotipo (carbonático, vulcânico, siliciclástico);

- Grau de continentalidade;

- Formações vegetais;

- Atributos da hidrologia (planície de inundação, delta, etc.);

- Complexidade e diversidade da estrutura morfológica.

Diferentemente dos anteriores, Viktor B. Sochava (1978), em seu livro Introdução à Teoria dos Geossistemas, sugere que a tipologia dos geossistemas não deva se basear nas características similares de tratos ou paisagens, mas na estrutura e dinâmica das fácies. Assim, para Sochava, a tipologia dos geossistemas (geômeros) deve ser realizada pelo agrupamento sucessivo de fácies (SUVOROV; SEMENOV; ANTIPOV, 2007), apresentando onze categorias de geômeros, a saber:

- Conjuntos de Tipos de Meios Naturais (Conjuntos de Tipos de Paisagens): inclui as grandes faixas geográficas da Terra (Ex.: Cinturão de Paisagens Boreais);

- Tipos de Meios Naturais (Tipos de Paisagens): grandes conjuntos naturais de uma faixa geográfica (Ex.: Taiga);

- Classes de Geomas: Divisões dos meios naturais com base no megarrelevo (Ex.: Montanhas Euroasiáticas);

- Subclasses de Geomas: divisões do megarrelevo com base em sua posição e outras características (Ex.: Montanhas de Baikal-Dzhugdzhursky);

- Grupos de Geomas: conjuntos naturais de uma subclasse de geoma (Ex.: Taiga Decidual de Baikal-Dzhugdzhursky);

- Subgrupos de Geomas: divisão de um grupo de geomas (Ex.: Taiga Decidual Montana);

- Geomas: agrupamento de classes de fácies com características estruturais e dinâmicas semelhantes. Ex.: Taiga Decidual de Bacia Intra-Montana

- Classes de Fácies: conjunto de grupos de fácies com características estruturais e dinâmicas semelhantes. Ex.: Depressões intermontanas e submontanas

- Grupos de Fácies: agrupamento de fácies com características estruturais e dinâmicas semelhantes. Ex.: Encostas com mescla de abeto musgo e arbustos.

- Fácies: segmento de relevo com mesmo substrato, tipo de solo e espécies vegetais dominantes. Ex.: Segmentos de encostas côncavas transeluviais com Stipa-Aneurolepidium em solo castanho comumente siltoso e carbonático salino.

- Geômero elementar (ainda fácies elementar ou biogeocenose) ${ }^{6}$ : estágio de transformação pedológica e sucessão vegetal num segmento geomórfico. Ex.: Stipa-Aneurolepidium em solo castanho comumente siltoso e carbonático salino.

\footnotetext{
${ }^{6}$ Para Sochava (1978), assim como para Solntcev (1967), uma biogeocenose não alterada pelo uso da terra é equivalente a uma fácies. Contudo, em áreas modificadas, uma mesma fácies pode apresentar diferentes associações de plantas, sendo necessário a diferenciação entre fácies e biogeocenoses.
} 
É interessante notar que, na taxonomia dos geossistemas, nem sempre todos os níveis podem ocorrer. A seguir destacamos o exemplo apresentado por Sochava em seu livro (Quadro 5). Nas páginas 225 e 226, o autor detalha a tipologia dos geossistemas para as Planícies e Planaltos da Sibéria Central, nota-se a ausência das seguintes categorias de geômeros: subclasses, grupos e subgrupos de geomas, bem como as classes de fácies.

Quadro 5. Exemplo de taxonomia de geossistemas.

\begin{tabular}{|c|c|}
\hline Categorias de geômeros & Exemplo \\
\hline $\begin{array}{l}\text { Conjunto de tipos de } \\
\text { paisagem }\end{array}$ & Cinturão de Paisagens Extratropicais Setentrionais \\
\hline Tipo de paisagem & Tundra Alpina da Ásia Setentrional e Taiga \\
\hline Classe de Geomas & Planícies e Planaltos da Sibéria Central \\
\hline \multirow[t]{3}{*}{ Geoma } & $\begin{array}{l}\text { Taiga central e taiga de lariço em afloramentos de planalto } \\
\text { dissecado e cadeias de colinas (Taiga clara de montanha) }\end{array}$ \\
\hline & $\begin{array}{l}\text { 1) Superfícies de aplanamento com vegetação arbustiva } \\
\text { pequena, herbáceas e musgo verde }\end{array}$ \\
\hline & 2) Encostas com mescla de abeto musgo e arbustos \\
\hline \multirow[t]{3}{*}{ Grupos de fácies } & $\begin{array}{l}\text { 3) Encostas em afloramentos com mescla de cedro, mirti- } \\
\text { los, pequenas ervas e musgo verde }\end{array}$ \\
\hline & $\begin{array}{l}\text { 4) Encostas com mescla de pinheiros, amieiro, gramíneas } \\
\text { (Limna), arbustos e musgos verdes }\end{array}$ \\
\hline & $\begin{array}{l}\text { 5) Encostas com pinheiros em rochas com líquens, musgos } \\
\text { e mirtilos }\end{array}$ \\
\hline
\end{tabular}

Fonte: Sochava, 1978, pp. 225-226.

Do ponto de vista metodológico, um aspecto relevante para identificação dos grupos de fácies é a utilização de informações geomorfológicas combinadas com informações vegetacionais. Sobre isso, Kuzmenko (2010) deixa claro que, trabalhando em grandes áreas, os grupos de fácies são as principais unidades iniciais de mapeamento. A partir delas é possível definir, por agrupamento, os geômeros de categoria superior (classes de fácies, geomas, subgrupos de geomas, etc.).

Neste ponto, o leitor pode achar que a teoria dos geossistemas ocupa-se única e exclusivamente da cartografia de área naturais. Contudo, a grande inovação trazida pela teoria foi a integração dos estudos sobre a estrutura, dinâmica e evolução das paisagens, indo muito além dos mapas e cartas. De acordo com Mamay (2007), Sochava foi pioneiro no estudo integrado das variações periódicas da paisagem, pelo estabelecimento de estações de monitoramento da dinâmica dos geossistemas. Dito isto, é importante que se compreenda o modo como a referida teoria passou a tratar a dimensão temporal das paisagens. 


\section{Geossistemas no tempo: dinâmica e evolução das paisagens}

Retomando a crítica de Sales (2004), sobre o fato de a dimensão temporal dos geossistemas não considerar as qualidades morfoestruturais das paisagens, limitando-se às variações de curto prazo, é preciso destacar pelo menos dois pontos:

- Os procedimentos de diferenciação de geossistemas regionais (cf. Sochava, 1978) e, daquilo que é chamado de regionalização físico-geográfica (cf. Isachenko, 1991), determinam áreas naturais de grandes dimensões pela correlação entre morfoestruturas e unidades bioclimáticas;

- Com isso, destaca-se o fato de que, a teoria dos geossistemas não se baseia puramente em um critério para análise da natureza (ex.: morfoestruturas), mas busca compreender as relações entre os diversos elementos e processos naturais, e isso traz uma série de implicações epistemológicas para o estudo e ensino da referida teoria (cf. tópico, a seguir).

A grande contribuição da teoria do geossistema foi a incorporação dos conceitos de invariantes e variáveis de estado, emprestados da física de sistemas dinâmicos. Aplicados à geografia, estes conceitos permitiram clarear e expandir os horizontes epistemológicos do estudo integrado da natureza, sem deixar de lado sua relação com as intervenções da sociedade.

Tratada como um sistema dinâmico, a paisagem passou a ser observada como um conjunto de componentes com temporalidades distintas, ou polissistemas, no dizer de Cherkashin (2008). Com base nisso, é possível distinguir duas categorias de geossistemas componentes (ou geocomponentes): aqueles que possuem uma taxa de mudança muito lenta (invariantes) e aqueles que possuem uma taxa de mudança mais rápida (variáveis de estado).

É possível então medir a idade da paisagem como a época em que a invariante se formou. Uma mudança na invariante significa uma evolução da paisagem, enquanto que as alterações nas variáveis de estado representam a dinâmica dos geossistemas. Traduzindo, grosso modo, para a geografia física, uma unidade geomorfológica (forma+estrutura superficial) corresponde à invariante do geossistema, enquanto os processos e elementos pedoedáficos, ecológicos, hídricos e atmosféricos representam as variáveis de estado.

Pensando sobre isso, Isachenko \& Reznikov (1996) propõem o termo sítio como unidade formada pela relação entre um tipo de substrato, sua forma de relevo e seu regime de drenagem. Em complemento, eles propõem que cada etapa de transformação pedológica e sucessão vegetal sobre um mesmo sítio seja denominada de estado.

Deste modo, os estados compreendem as mudanças ocorridas na paisagem a partir do estabelecimento do sítio, mas que não impliquem na mudança completa de suas características (ISACHENKO, 2007). A partir do momento em que um sítio se estabelece, toma lugar uma série de transformações pedogenéticas, ecossistêmicas e atmosféricas sobre ele. Cada uma destas transformações compreende um estado.

É similar ao conceito de balanço entre morfogênese e pedogênese de Tricart (1977). Quando os processos formadores do relevo estão em ação intensa, não há possibilidade de formação de solos nem de exploração biológica do substrato, é a invariante em transformação (evolução da 
paisagem). De outro modo, quando cessa a atividade geomorfológica intensiva, toma lugar a transformação pedológica e a dinâmica dos seres vivos (sucessão vegetal).

É claro que isso se dá em escalas concomitantes à magnitude dos processos envolvidos. Um deslizamento pode ser suficiente para fazer evoluir uma fácies ou mesmo um geócoro elementar (subtrato - podurochische), mas não uma paisagem (landschaft - Macrogeócoro). Neste sentido, diferentes métodos permitem abordar escalas distintas, não apenas em termos de resolução espacial, mas também temporal. Por exemplo, algumas técnicas de análise e datação de perfis estratigráficos (a exemplo da Luminescência Opticamente Estimulada - LOE, associada a análises sedimentológicas e morfoestratigráficas), permitem determinar não apenas a idade e natureza da invariante atual, mas também o conhecimento de quadros sucessivos de paleopaisagens.

Deste ponto de vista, é só a partir da visão geossistêmica que se torna possível tratar dados de fontes diversas (geomorfológicas, sedimentológicas, palinológicas, fitólitos, etc.) dentro de um mesmo horizonte epistemológico, transportando a geografia física ao status de ciência histórica (CORRÊA, 2006). Contudo, apesar de os estudos evolutivos auxiliarem na compreensão de paleopaisagens, eles não são suficientes para explicar o funcionamento da paisagem atual, emergindo assim, a necessidade de estudos dinâmicos e funcionais.

É neste sentido, que a consideração da dinâmica das paisagens permitiu (e permite) à geografia integrar estudos evolutivos às perspectivas de monitoramento ambiental, na busca de conhecer estágios funcionais e acompanhar com precisão as mudanças em patamares formativos de novos geossistemas, sobretudo através do desenvolvimento do conceito de estados da paisagem.

Os estados da paisagem (ou Estados do Complexo Territorial) abrangem as variações que um geossistema apresenta em seu funcionamento (dinâmica). De forma mais abrangente, os estados da paisagem atual incluem três categorias de fenômenos, a saber: de curto prazo (duração inferior a 24h), médio prazo (>24h a 1 ano) e de longo prazo (>1 ano) (BERUCHASHVILI, 1989).

Para o estudo da dinâmica da paisagem, Sochava propôs o monitoramento estacional e semiestacional, sendo o primeiro de caráter fixo e com objetivo de controle das observações e, o segundo, de caráter variável e com observações em intervalos de tempo mais largos, com o objetivo de melhor espacialização das informações (SOCHAVA, 1978). Na época da URSS, foram estabelecidas 20 estações fixas no território soviético, entretanto, algumas destas não puderam ser mantidas com o fim do regime comunista (MAMAY, 2007).

Seguindo o modelo de estudos estacionais desenvolvido por Viktor Sochava, foi construída na Geórgia (região de Martkopi) uma estação físico-geográfica que chega a mensurar entre 6 e 7 mil medidas diárias em 100 diferentes atributos das paisagens e funciona há mais de 40 anos. A partir dos resultados obtidos pelo monitoramento na estação de Martkopi (Geórgia), seu proponente, o geógrafo Nikolai Levanovich Beruchashvili propôs o conceito de Estado do Complexo Territorial (Stexe). ${ }^{7}$

Um stexe é definido por um regime homogêneo de trocas de matéria e energia num determinado geossistema. Os estudos estacionais têm demonstrado que um stexe geralmente dura um

\footnotetext{
${ }^{7}$ Stexe é uma sigla para sostoiania territorialniykh komplexov ou Ctekc (Состояния Территориальных Комплексов), em russo. Em português significa Estado do Complexo Territorial.
} 
dia, mas pode prolongar-se por vários dias, podendo atingir um mês ou mais (ISACHENKO, 1998).

Para ser mais claro, o monitoramento de geossistemas assemelha-se ao que tem chamado de Pesquisa Ecológica de Longa Duração. Em particular, busca definir aspectos geofísicos e geoquímicos dos geossistemas. Isso inclui: definir o balanço de radiação, o balanço hídrico, a produtividade de biomassa, a decomposição de serapilheira, a circulação de sedimentos, nutrientes, metais pesados e outras substâncias.

Como exemplo, observe a fotografia abaixo (Fig. 5). Ela apresenta duas fácies distintas: uma encosta rochosa com bromélias e um tálus com árvores e arbustos. Agora pense sobre os processos naturais citados no parágrafo anterior. É fácil perceber como os referidos processos (ex.: balanço hídrico) podem variar de uma fácies para outra.

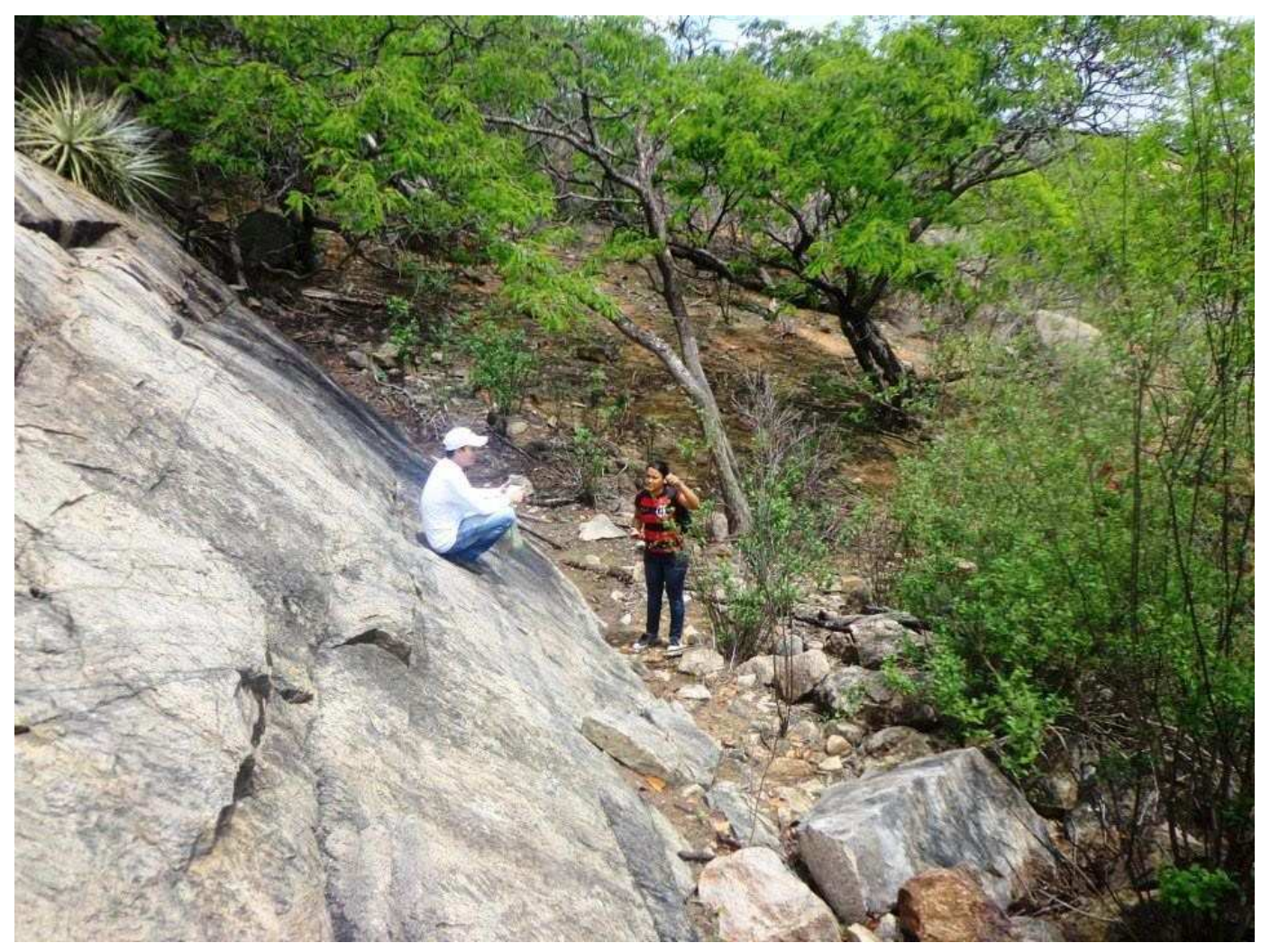

Figura 5. À esquerda: encosta rochosa com bromélias. À direita: tálus com árvores e arbustos. Diferentes geossistemas possuem diferentes taxas de operação de processos naturais. Fonte: Ferreira Júnior em CAVALCANTI (2014).

Como foi dito, os estudos estacionais permitem auxiliar na compreensão dos processos evolutivos, mas ambos carecem da fonte primária, representada pelos estudos estruturais, que têm, na cartografia e classificação dos geossistemas, seu principal objetivo. Assim, a cartografia e classificação sistemática das paisagens, além de fornecerem informações preciosas ao planejamento territorial, servem de estratificação da amostragem para determinação de pontos de coleta 
para estudos evolutivos, tanto quanto para seleção de áreas para observações fixas (estacionais) e variáveis (semiestacionais).

Esta integração e interdependência de perspectivas estruturais, dinâmicas e evolutivas, permitida pelo horizonte epistemológico da teoria dos geossistemas, nos leva à necessidade de uma reflexão sobre o lugar do estudo de geossistemas no âmbito formal da geografia científica.

\section{O estudo de geossistemas pertence a qual área da Geografia?}

Acima, havíamos dito que o Estudo de Geossistemas é similar ${ }^{8}$ ao que se chama na Rússia de Ciência da Paisagem e Regionalização Físico-Geográfica. Contudo, cabe uma pergunta quanto à natureza epistemológica deste direcionamento de estudo: a qual área da geografia pertence?

Analisando o contexto de aplicação do termo geossistema, poderíamos traçar várias hipóteses, incluindo-o na geomorfologia dinâmica, na biogeografia ecológica ou mesmo numa climatologia geográfica ou ecologia/geoecologia da paisagem. Entretanto, vamos preferir analisar o contexto da geografia russa, onde esta epígrafe se desenvolveu.

Observando os trabalhos da $11^{\text {a }}$ Conferência Internacional da Paisagem (realizada em 2006, em Moscou), que foram reunidos em um livro contendo 31 artigos, podemos observar que o primeiro deles se dedica a explanar daquilo que se trata a Ciência da Paisagem russa. $\mathrm{O}$ autor, Kiril N. Dyakonov (2007) aponta cinco direcionamentos gerais desta disciplina: genético-estrutural, dinâmico-funcional, evolucionário/paleopaisagístico, antropogênico e cultural-histórico.

A linha genético-estrutural estuda a gênese e estrutura das paisagens (geossistemas), sua diversidade nos níveis locais, regionais e planetários. É uma abordagem característica das sínteses naturalistas, tais como os domínios de natureza de Aziz N. Ab'Saber, das unidades geoambientais de Silva et al. (2001) e outros similares;

A direção dinâmico-funcional tem interesse no funcionamento atual das paisagens, sobretudo a partir de ferramentas geoquímicas e geofísicas. Exemplos são os estudos geoquímicos de Nascimento et al. (2008), e do ponto de vista geofísico, no contexto da Climatologia Geográfica de Carlos Augusto de Figueiredo Monteiro e dos estudos sobre balanço hídrico e de radiação;

O direcionamento evolucionário ou paleopaisagístico está preocupado com o desenvolvimento das paisagens, principalmente no Holoceno e Pleistoceno. Envolve questões paleoambientais (Geomorfologia do Quaternário, Paleoclimatologia, Paleobotânica, etc.), tais como aquelas discutidas por Corrêa (2006) e Silva (2013);

A linha antropogênica foca no desenvolvimento das paisagens provocado pela atividade humana, avaliação de impactos das atividades econômicas e riscos para a saúde humana. Em termos da geografia brasileira, corresponderia à ideia de geografia física aplicada, a exemplo do modelo de vulnerabilidade ambiental de Crepani et al. (2001);

\footnotetext{
${ }^{8}$ A Ciência da Paisagem ainda é mais ampla que o estudo de geossistemas, na medida em que abarca a dimensão imaterial da paisagem e não apenas seu sentido físico-natural (Cf. o viés cultural-histórico, a seguir).
} 
O viés cultural-histórico é preocupado com as paisagens criadas materialmente e espiritualmente pela sociedade, focando em aspectos estéticos, patrimoniais, fenomenológicos e etnográficos (KALUTSKOV, 2007). Este interesse acadêmico é muito próximo ao que se convencionou chamar no Brasil de Geografia Cultural.

Não obstante toda esta gama de direcionamentos, a Ciência da Paisagem não esgota as atividades da geografia russa, pelo contrário, ela é apenas um entre diversos de seus componentes, ou seja, ela é tratada como uma disciplina à parte da geomorfologia, climatologia, biogeografia, pedologia, da hidrologia, geografia econômica e assim por diante.

Todavia, não se compreende isto sem que antes seja buscado um entendimento da estrutura acadêmica da geografia como é praticada na Rússia. Deste modo gostaríamos de sumarizar alguns aspectos, tais como:

$\mathrm{Na}$ antiga URSS, o curso de Geografia recebeu o prestígio de possuir uma faculdade voltada unicamente para seu estudo, organizada em departamentos exclusivos para cada uma de suas disciplinas especializadas (Geomorfologia, Climatologia, Biogeografia, Geografia Econômica, Cartografia, Ciência da Paisagem, entre outros). Existe um departamento inteiro exclusivo para a prática da Ciência da Paisagem, onde os alunos fazem um curso de cinco anos e estudam detalhadamente cada um de seus direcionamentos.

No Brasil, esta disciplina nem mesmo existe e seu conteúdo, como vimos acima, é fragmentado em diversas outras disciplinas (climatologia, geografia cultural, etc.) o que dificulta ainda mais o seu entendimento. Isto ocorre por pelo menos quatro motivos:

- No Brasil, o ensino superior da Geografia foi sempre organizado em um único departamento, geralmente nas faculdades de Ciências da Terra ou Ciências Humanas;

- No século XX os geógrafos soviéticos conduziram a organização de sua ciência numa preocupação de explicá-la com base no materialismo histórico e da sua utilidade para o então Estado socialista. No Brasil, sobretudo no último quartel do mesmo século, ganhou força uma proposta de revisão da geografia que então servia ao Estado (capitalista), muitas vezes esquecendo-se das desigualdades sociais;

- Em resultante disso, na URSS pôde crescer com mais facilidade uma perspectiva geográfica como ciência da Terra e da sociedade, valorizando tanto a promoção de abordagens integrativas quanto especializadas ignorando, contudo, questões relativas às desigualdades sociais e que poderiam ameaçar a imagem do Estado.

- No Brasil, sobretudo a partir da década de 1970, o crescimento de uma perspectiva marxista, no contexto de profundas desigualdades sociais do país, fomentou intensos debates que resultaram na supervalorização do papel político da disciplina. Este fato foi acompanhado de uma consequente desvalorização das temáticas da natureza, principalmente aquelas tais como a Geomorfologia Estrutural, Paleoclimatologia e Morfotectônica. Numa abordagem reducionista, muitos chegaram a afirmar que estas temáticas não pertenciam à Geografia, no que Sales (2004) denominou de uma tentativa de eliminar a Geografia Física do Brasil. Este foi, sem dúvida, um dos maiores erros de alguns dos adeptos da geografia crítica brasileira. 
Considerando estas informações sobre os diferentes contextos, fica mais fácil compreender as diferenças nos horizontes cognitivos de geógrafos brasileiros e russo-soviéticos. Distinguem-se em termos de contexto político, estrutura acadêmica e história de desenvolvimento do conhecimento geográfico.

\section{Conclusões}

Este trabalho tentou apresentar uma sucinta descrição da teoria dos geossistemas nos termos da geografia russo-soviética, a fim de desvinculá-la daquela perspectiva francesa, Bertrandiana de 1968, que tanto tem dominado as interpretações realizadas pelos geógrafos brasileiros e que, desconsideram as próprias mudanças de concepção do pesquisador de Toulouse.

$\mathrm{Na}$ geografia inicial de Georges Bertrand, o geossistema tratava-se de uma unidade mesorregional da paisagem, da $4^{\mathrm{a}}$ ou $5^{\mathrm{a}}$ ordem de grandeza na escala de Cailleux e Tricart. Contudo, é na geografia soviética, que o termo geossistema passa a ser associado a uma teoria explicativa das relações entre os diversos campos da geografia física. Neste sentido, a teoria dos geossistemas de Sochava consiste numa proposição realista acerca da estrutura, dinâmica e evolução de áreas naturais derivadas das relações entre os componentes da natureza.

Nesta visão realista, a referida teoria se baseia na aceitação da existência real de determinadas unidades físico-geográficas, bem como nas relações de trocas de matéria e energia no âmbito dos diferentes sistemas ambientais que compõem a superfície terrestre. Assim, destacam-se os conceitos de invariantes e variáveis de estado para compreensão das relações entre os componentes da natureza.

O horizonte epistemológico alcançado pela teoria dos geossistemas permitiu integrar, de modo mais homogêneo, perspectivas estruturais, dinâmicas e evolutivas para o estudo de áreas naturais no âmbito da Geografia. Apesar disso, a teoria em questão apresenta certa dificuldade de interpretação e aceitação no Brasil por vários motivos. Isto ocorre em função dos seguintes obstáculos:

- Larga divulgação do texto de Bertrand de 1968/1972, sem conhecimento de sua publicação posterior com Beroutchachvili em 1978 ou mesmo de seu modelo GTP;

- Falta de compreensão da diferença entre o conceito de geossistema em Sochava e em Bertrand 72, que partilham apenas a mesma epígrafe;

- Pouco material disponível em português, sobre as ideias de Sochava e de outros geógrafos russo-soviéticos e;

- Diferenças na organização da estrutura acadêmica e história do pensamento geográfico no Brasil e nos países formadores da antiga URSS.

Por fim, podemos considerar que muitas interpretações e até críticas pouco assertivas à teoria dos geossistemas de Sochava, feitas por geógrafos brasileiros, foram realizadas sem o devido conhecimento da proposta do geógrafo russo. Nestes termos, estas críticas e interpretações, en passant, realizadas sumariamente, com base apenas em textos disponíveis em português e lín- 
guas mais acessíveis (principalmente o francês), mais prejudicam do que colaboram construtivamente com o debate sobre áreas naturais, sua classificação e estudo. Debate este que traz a promessa de tornar a geografia brasileira ainda mais rica do que já é, mormente pela incorporação de elementos de geografias tão distintas quanto àquelas das terras da Rússia e arredores.

Cabe destacar que a grande vantagem da teoria dos geossistemas é que ela permite investigar diferentes aspectos da natureza (estrutura, dinâmica e evolução) sob uma base unificada em termos de perspectiva e tratamento dos problemas. Entretanto, vale a ressalva de que é preciso um direcionamento distinto, do ponto de vista epistemológico (e isso tem implicações curriculares) para seu estudo. Não obstante, os geógrafos brasileiros precisam passar a se ver, sem medo, e também, como praticantes de uma geografia física compromissada com a melhoria da qualidade ambiental.

De um ponto de vista prático, é preciso que os geógrafos brasileiros (aqueles interessados no estudo de geossistemas) se engajem e busquem a integração entre levantamentos sistemáticos dos geossistemas (cartografia de paisagens), pesquisas ecológicas de longa duração (com ênfase no monitoramento dos geossistemas), estudos de reconstrução paleoambiental e na avaliação do efeito das intervenções da sociedade sobre os geossistemas.

Submetido em 30 de setembro de 2016. 
Referências

AB'SABER, A. N. Os domínios de natureza no Brasil: potencialidades paisagísticas. São Paulo: Ateliê Editorial, 2003. 159p.

BEROUTCHACHVILI, N.L. e BERTRAND, G.. Le Géosystème ou Système territorial naturel. Revue Géographique des Pyrénés et du sud-ouest. Toulose. 1978. p. 167-180.

BERTRAND, G. Paysage et géographie physique globale: esquisse méthodologique. Revue géographique des Pyrénées et sud-ouest, v. 39, fasc. 3, 1968. p. 249-272.

BERTRAND, G.; BERTRAND, C. Uma geografia transversal e de travessias: o meio ambiente através dos territórios e das temporalidades. Maringá: Massoni, 2007. 332p.

BERUCHASHVILI, N.L. Ecologia da Paisagem e Cartografia dos Estados do Meio Natural. Tbilisi: Editora da Universidade de Tbilisi. 1989. 196p. (em russo)

BRACKEN, L.J.; WAINWRIGHT, J. 'Equilibrium in the balance? Implications for landscape evolution from dryland environments', In: Gallagher, K.; Jones, S.; Wainwright, J. (eds) Landscape Evolution: Temporal and Spatial Scales of Denudation, Climate and Tectonics. London: Geological Society Special Publication. v.296. 2008, p.29-46.

BRIERLEY, G.J.; FRYIRS, K. River Styles, a geomorphic approach to catchment characterization: implications for river rehabilitation in Bega Catchment, New South Wales, Australia. Environmental management. v.25. n.6. 2000. p.661-679.

CAVALCANTI, L.C.S. Cartografia de paisagens: fundamentos. São Paulo: Oficina de textos. 2014. 96p.

CAVALCANTI, L.C.S.; CORRÊA, A.C.B. Da descrição de áreas às sínteses naturalistas: uma abordagem historiográfica sobre a ideia de 'áreas naturais'. Espaço e Geografia (UNB). v.17 n.2. 2014. p.377-422.

CAVALCANTI, L.C.S.; CORRÊA, A.C.B.; ARAÚJO FILHO, J.C. Geosystems of Alagoas State. Regional Conference on Geography - International Geographic Union. Santiago, Chile. 2011.

CAVALCANTI, L. C. S. Da Descrição de Áreas à Teoria dos Geossistemas: uma Abordagem Epistemológica sobre Sínteses Naturalistas. Tese (Doutorado em Geografia). Recife: UFPE. 2013. 217f.

CAVALCANTI, L. C. S. Geossistemas do Estado de Alagoas: uma contribuição aos estudos da natureza em geografia. Dissertação (Mestrado em Geografia). Recife: UFPE. 2010. $132 f$.

CAVALCANTI, L.C.S.; SANTOS, L.S.; CORREA, A.C.B.; ARAÚJO FILHO, J.C. Técnicas de campo para descrição de geossistemas: reconhecimento expedito na borda oeste do maciço residual de Poço das Trincheiras, Alagoas. Geoambiente On-line, v. 15, 2010. p.72-102.

CHERKASHIN, A.K. Geographical systemology: formation rules for system ontologies. Geography and natural resources v.29, n2. 2008. p.110-115. 
CHERKASHIN, A.K. Modern problems of landscape geomorphology as a science of cause and effect of spatial differentiation of the territory. In: Relief and exogenous processes of mountains. Irkustk: Viktor B. Sochava Institute of Geography. 2011. p.48-52. (em russo).

CHERNYKH, D.V. \& ZOLOTOV, D.V. Landscape hierarchy and landscape diversity (contact zones of lowland and mountain countries as a case study). In: DYAKONOV, K.N., KASIMOV, N.S., KHOROSHEV, A.V., KUSHLIN, A.V. Landscape analysis for sustainable development: theory and applications of Landscape Science in Russia. Alexplublishers: Moscow. 2007. p.121-126.

CORRÊA, A.C.B. O geossistema como modelo para a compreensão das mudanças ambientais pretéritas: uma proposta de geografia física como ciência histórica. In: Sá, A.J. \& CORREA, A.C.B. Regionalização e análise regional. Perspectivas e abordagens contemporâneas. Recife: Editora Universitária da Universidade Federal de Pernambuco, 2007, p. 33-45.

CREPANI, E.; MEDEIROS, J.S.; HERNANDEZ FILHO, P.; FLORENZANO, T.G.; DUARTE, V.; BARBOSA, C.C.F. Sensoriamento Remoto e Geoprocessamento Aplicados ao Zoneamento Ecológico Econômico e ao Ordenamento Territorial. São José dos Campos, 2001. 124p.

DYAKONOV, K.N. Landscape studies in Moscow Lomonosov State University: development of scientific domains and education. In: DYAKONOV, K.N., KASIMOV, N.S., KHOROSHEV, A.V., KUSHLIN, A.V. Landscape Analysis for sustainable development: theory and applications of landscape science in Russia. Moscou: Alexplublishers, 2007. p. 11-20.

EGOROV, I.E. Práticas de campo em Ciência da Paisagem. ljevsk: Universidade Estatal de Udmurt. 72p. Em russo.

HACKING, I. Ontologia histórica. São Leopoldo: UNISINOS. 2009. 306p.

HAY, G.J.; MARCEAU, D.J. Multiscale object-specific analysis (MOSA): An integrative approach for multiscale analysis. In: DE JONG, S.; VAN DER MEER, F. (eds) Remote Sensing Image Analysis: Including the Spatial Domain. Kluwer Academic Publishers, 2004. p.71-92.

ISACHENKO, A.G. Ciência da Paisagem e Regionalização Físico-Geográfica. Moscou: Vyshaya Shkola. 1991. 370p. Em russo.

ISACHENKO, A.G. Principles of Landscape Science and Physical Geographic Regionalization. Melbourne. 1973. 311p.

ISACHENKO, A.G.; SHLIAPNIKOV, A.A. Paisagens. Moscou: MISL. 1989. 504p. Em russo.

ISACHENKO, G.A. Long-term conditions of Taiga landscapes of European Russia. In: DYAKONOV, K.N., KASIMOV, N.S., KHOROSHEV, A.V., KUSHLIN, A.V. Landscape Analysis for sustainable development: theory and applications of landscape science in Russia. Moscou: Alexplublishers, 2007. p.144-155.

ISACHENKO, G.A.; REZNIKOV, A.I. Landscape dynamics of northwest Taiga of European Russia. São Petersburgo: Universidade Estatal de São Petersburgo. 1996. em russo.

KALESNIK, S.V. General geographic regularities of earth. Annals of the American Association of Geography. 1964. p.160-164. 
KALUTSKOV, V.N. Cultural landscapes in the Russian geographical tradition In: DYAKONOV, K.N., KASIMOV, N.S., KHOROSHEV, A.V., KUSHLIN, A.V. Landscape analysis for sustainable development: theory and applications of Landscape Science in Russia. Alexplublishers: Moscow. 2007. p.239-246.

KHOROSHEV, A.V.; MEREKALOVA, K.A.; ALESCHENKO, G.M. Multiscale organization of intercomponent relations in landscape. In: DYAKONOV, K.N., KASIMOV, N.S., KHOROSHEV, A.V., KUSHLIN, A.V. Landscape analysis for sustainable development: theory and applications of Landscape Science in Russia. Alexplublishers: Moscow. 2007. p.93-103.

KRAUKLIS, A.A. Problemas de Ciência da Paisagem Experimental. Novasibéria: Nauka. 1979. 233p. Em russo.

KUZMENKO, E.I. Cartographic Approach in Studying the Structure and Dynamics of Geosystems as Exemplified by the Middle Ob Region. Geography and Natural Resources. Vol. 32, No. 2, 2011. p.160-167.

LOPES, A.N. A Bíblia e seus intérpretes: uma breve história da interpretação. São Paulo: Cultura Cristã, 2004. 287p.

MAMAY, I.I. Landscape Science in Russia in the early XXI century: state and methodological problems. In: DYAKONOV, K.N., KASIMOV, N.S., KHOROSHEV, A.V., KUSHLIN, A.V. Landscape Analysis for sustainable development: theory and applications of landscape science in Russia. Moscou: Alexplublishers, 2007. p.21-28.

MONTEIRO, C. A. F. Teoria e Clima Urbano. (tese de Livre Docência apresentada ao Depto de Geografia/FFLCH-USP). São Paulo, 1976.

MONTEIRO, C.A.F. Geossistemas: a história de uma procura. São Paulo: Contexto/GeoUSP. (Novas abordagens 3). 2000. 127p.

NASCIMENTO, F. R.; SAMPAIO. J. L. F. Geografia Física, geossistemas e estudos integrados da paisagem. Revista da Casa da Geografia de Sobral, vol.6/7, no.1, 2005. p.167-178.

NASCIMENTO, N.R.; FRITSCH, E.; BUENO, G.T.; BARDY, M.; GRIMALDI, C.; MELFI, A.J. Podzolization as a deferralitization process: dynamics and chemistry of ground and surface waters in an Acrisol-Podzol sequence of the upper Amazon Basin. European Journal of Soil Science. 2008. p.1-14.

NIKOLAEV, V.A. Problemas de Ciência da Paisagem Regional. Moscou: Universidade Estatal de Moscou. 1979. 160p. Em russo.

RODRIGUEZ, J.M.M.; SILVA, E.V.; CAVALCANTI, A.P.B. Geoecologia das paisagens: uma visão geossistêmica da análise ambiental. 2.ed. Fortaleza: Edições UFC. 2004. 222p.

SALES. V.C. Geografia, sistemas e análise ambiental: abordagem crítica. GEOUSP - Espaço e Tempo. № 16, 2004. p.125-141.

SEMENOV, Y.M.; SNYTKO, V.A. The 50th Anniversary of the Appearance of V. B. Sochava's First Article on the Geosystem. Geography and Natural Resources. Vol. 34, No. 3, 2013. p.5-8. 
SILVA, D.G. Reconstrução da Dinâmica Geomorfológica do Semiárido Brasileiro no Quaternário Superior a Partir de uma Abordagem Multiproxy. Tese (Doutorado em Geografia). Recife: UFPE. 2013. 277p.

SILVA, F.B.R., SANTOS, J.C.P., SILVA, A.B., CAVALCANTI, A.C., SILVA, F.H.B.B., BURGOS, N., PARAHYBA, R.B.V., OLIVEIRA NETO, M.B., SOUZA NETO, N.C., ARAÚJO FILHO, J.C., LOPES, O.F., LUZ, L.R.Q.P., LEITE, A.P., SOUZA, L.G.M.C., SILVA, C.P., VAREJÃOSILVA, M.A., BARROS, A.H.C. Zoneamento Agroecológico do Estado de Pernambuco. Recife: Embrapa Solos - Unidade de Execução de Pesquisa e Desenvolvimento - UEP Recife; Governo do Estado de Pernambuco (Secretaria de Produção Rural e Reforma Agrária), 2001. CD-ROM.- (Embrapa Solos. Documentos; no. 35).

SOCHAVA, V.B. Algumas noções e termos da Geografia Física. Relatórios do instituto de Geografia da Sibéria e do Extremo Oriente. 3. 1963. p.53.

SOCHAVA, V.B. Introdução à Teoria do Geossistema. Novasibéria, Nauka, 1978. 320p. Em russo.

SOCHAVA, V.B. O estudo de geossistemas. Métodos em questão, n.16, IGUSP. São Paulo, 1977. $51 \mathrm{p}$.

SOLNETSEV, N.A. The natural geographic landscape and some of its general rules. In: WIENS, J.A.; MOSS, M.R.; TURNER, M.G.; MLADENOFF, D.J. Foundation papers in Landscape Ecology. Columbia: Columbia University Press. 2006. p.19-27.

SOLNTCEV, N.A. What is the difference between facies and biogeocenosis. Series Geography. n.2. 1967. (Em russo). Disponível em:

<http://www.landscape.edu.ru/book/book_solncev_2001_184.shtml> acesso em 08 nov 2016.

SUVOROV, E.G.; SEMENOV, Y.M.; ANTIPOV, A.N. Concept of landscape information renovation for Siberia area. In: DYAKONOV, K.N., KASIMOV, N.S., KHOROSHEV, A.V., KUSHLIN, A.V. Landscape Analysis for sustainable development: theory and applications of landscape science in Russia. Moscou: Alexplublishers, 2007. p.80-92.

TRICART, J.F.L. Ecodinâmica. Rio de Janeiro, FIBGE/SUPREN. 1977. 91p.

TRICART, J.F.L.; CAILLEUX, A. Le problème de la classification des faits géomorphologiques. Annales de Géographie. t.65, n.349, 1956, p.162-186.

TROPPMAIR, H.; GALINA, M.H. Geossistemas. Mercator. 5, n.10. 2006. p.79-89.

VEYRET, Y; VIGNEAU, J.P. Geographie Physique: Milieux Et Environnement Dans Le Systeme Terre. Paris: Armand Colin. 2002.

VICENTE, L.E.; PEREZ FILHO, A. Abordagem sistêmica e Geografia. Geografia. Rio Claro, v.28, n. 3., 2003. p.323-344.

WALTER, H. Vegetação e zonas climáticas: tratado de ecologia global. São Paulo: E.P.U., 1986, 325p.

ZUCHKOVA, V.K.; RAKOVSKAIA, E.M. Métodos de Investigação em Geografia Física Integrada. Moscou: Academiia. 2004. 368p. em russo. 